\title{
Continuum Robots for Manipulation Applications: A Survey
}

\author{
Srikanth Kolachalama $(D)$ and Sridhar Lakshmanan \\ Department of Electrical and Computer Engineering, University of Michigan, Dearborn 48128-1491, USA \\ Correspondence should be addressed to Srikanth Kolachalama; skola@umich.edu
}

Received 11 February 2020; Accepted 11 June 2020; Published 18 July 2020

Academic Editor: Weitian Wang

Copyright (c) 2020 Srikanth Kolachalama and Sridhar Lakshmanan. This is an open access article distributed under the Creative Commons Attribution License, which permits unrestricted use, distribution, and reproduction in any medium, provided the original work is properly cited.

\begin{abstract}
This paper presents a literature survey documenting the evolution of continuum robots over the past two decades (1999-present). Attention is paid to bioinspired soft robots with respect to the following three design parameters: structure, materials, and actuation. Using this three-faced prism, we identify the uniqueness and novelty of robots that have hitherto not been publicly disclosed. The motivation for this study comes from the fact that continuum soft robots can make inroads in industrial manufacturing, and their adoption will be accelerated if their key advantages over counterparts with rigid links are clear. Four different taxonomies of continuum robots are included in this study, enabling researchers to quickly identify robots of relevance to their studies. The kinematics and dynamics of these robots are not covered, nor is their application in surgical manipulation.
\end{abstract}

\section{Introduction}

1.1. Why Continuum Robots? In the manufacturing industry, robots have steadily gained importance in assembly-line operations due to their compelling value proposition: reduced cycle-time and increased accuracy, along with a skillset [1]. A typical industrial robot is floor-mounted for safety and consists of discrete rigid links that are actuated for gross movement of the end effector and of a task-appropriate end effector with fine motor control. Sophisticated control software operates individual robots or coordinates multiple robots in order to maximize their value in a specific industrial operation [2].

Against this backdrop, continuum robots are emerging as a novel concept, at least in research, with the potential to be used across a wide range of industrial applications [3]. Continuum robots are hyperflexible electromechanical structures with infinite degrees of freedom which provide them with the ability to maneuver complex curvilinear pathways (a survey on continuum manipulators [4]). A key advantage of continuum robots over those with rigid links is that, due to their considerably lower weight for the same maximum output force, they can be ceiling-mounted as opposed to floor-mounted. This advantage significantly increases their safety when they are used in joint operations with humans on the factory floor [5]. On the flip side, continuum robots are inherently more nonlinear and thereby harder to control than their discrete rigid-link counterparts, thereby presenting a barrier to adoption in the industry [6].

Continuum robots have increased flexibility, and thereby dexterity, compared to their rigid-link counterparts (the importance of continuum robots [7]). Figure 1 from [8] illustrates the essential difference between a discrete, a serpentine, and a continuous-link structure. It is clear from this figure that continuum structures have more degrees of freedom to move, and thereby, they are able to move more precisely along the shape of an object. In addition, their ends can position themselves in many more 3D facing directions compared to rigid-link structures. Researchers are developing continuum robots for a variety of navigation [9] and exploration [10], manufacturing and assembly [11], and medical and surgical applications [12].

1.2. Bioinspired Robots. When it comes to continuous actuated structures, biological systems from nature (Figure 1) have some compelling characteristics worth mimicking: symmetric and optimized design, evolution-enabled uniqueness for the task at hand, and, finally, energy-efficient kinematics and dynamics for survival (survey of bioinspiration [13]). Researchers have been inspired by the animal and plant kingdoms when it comes to designing their continuum robots, and Table 1 presents our first 


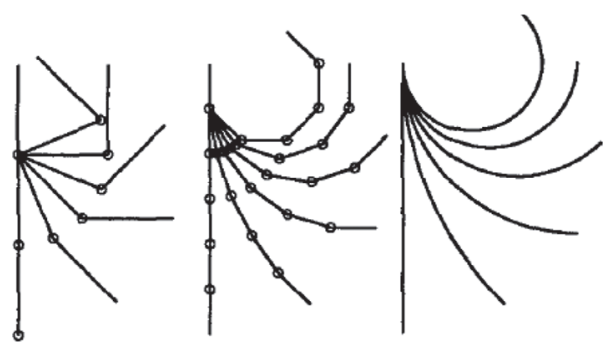

Discrete

Serpentine

Continuum

Figure 1: Differentiation-linked and continuum [8].

TABLE 1: The robots surveyed herein mapped per their bioinspiration.

Elephant trunk

Spine of a mammal

Snake

Octopus arm

Tentacle

[84-103], [104-113], [114-131]

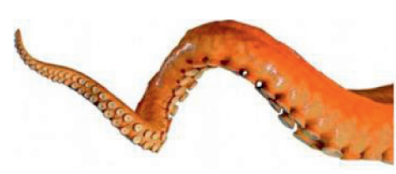

[32-55]

[56-71]

[72-83]
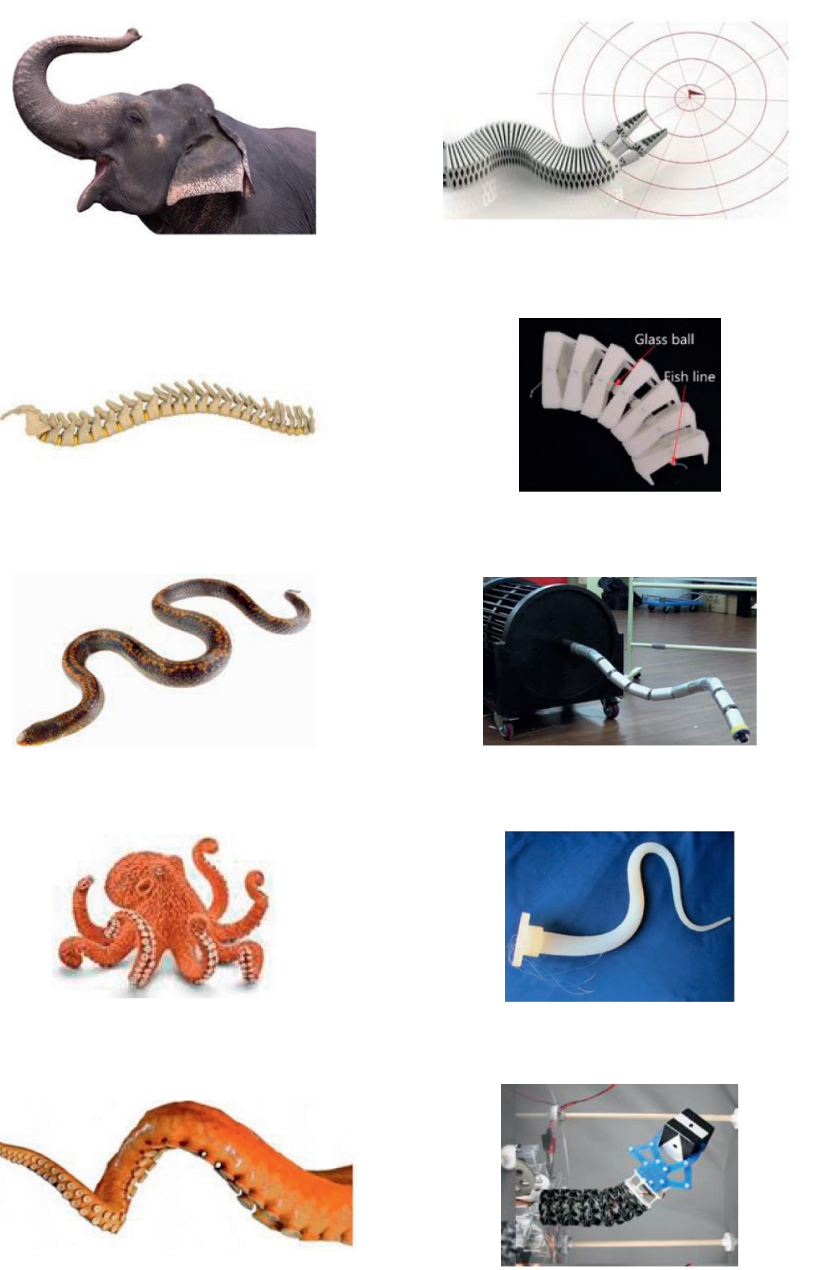

Human arm and finger

[132-159] 
TABLE 1: Continued.

\begin{tabular}{llll}
\hline Bioinspiration & Reference & Model & Continuum robot (example)
\end{tabular}

Biological vine and plant

$[160-181]$

Tongue and tail of a reptile
$[182,183]$

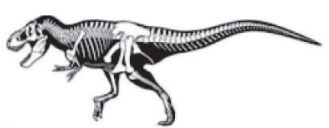

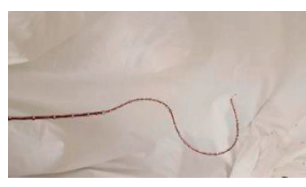

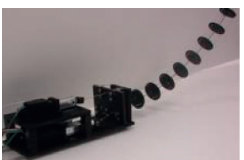

taxonomy, namely, the bioinspiration behind various robots surveyed herein: our survey includes multiple references to Walker's research group publications-they are not only one of the earliest to investigate biological structures for continuum robots, starting with the elephant's trunk [27], but they have also had the largest footprint of any research group, the left column of Table 1 [14-31].

1.3. Survey Organization. Continuously articulated structures in the bio-kingdom are made up of muscles, tendons, fibers, and joints. One of the three focus areas of this paper is a survey and taxonomy of continuum robots from the standpoint of their mechanical structure (Section 2). The influence of the bio-kingdom on continuum robots is so complete that an overwhelming majority of continuum robots are made of soft materials that allow these robots to have the required flexibility. The second focus area of this paper is a survey and taxonomy of continuum (soft) robots in terms of materials (Section 2). Continuous robotics use hydraulic, pneumatic, and electrical actuators. Our final taxonomy of continuum robots is based on a survey of the types of actuators used to achieve their motion (Section 4). The paper concludes with some broad remarks regarding the robots surveyed and some observations on where the field is headed (Section 5). More than two hundred references are cited herein, and the citation details are at the end of this paper (References). We reiterate that the kinematics and dynamics of these robots, including sensors and control, as well as their application in various surgical applications, are beyond the scope of this paper. For those topics, we refer to the following excellent surveys: $[12,184,185]$.

\section{Structure and Material}

The taxonomy and evolution, along with the materials used, of continuum robot development inspired by biostructures are discussed in this section.
2.1. Structure. The structure of the continuum robot used for manipulation is broadly classified into a single or multisegment robot in the early phases of research [186]. In order to enhance the functionality, multiple discs are inputted as a backbone for these robots in order to mimic a continuum structure, examples of which are shown in Table 2. Every continuum robot developed falls into the category of bioinspiration mentioned in Table 1, and the description in Table 2 provides a brief outline of the models developed.

In the early phases of research [14-20], known as firstgeneration continuum robots, the elephant trunk models [187] were constructed with a maximum of three segments with pneumatic actuation. Jones and Walker, along with researchers at Clemson University, had developed two robots, OctArm [14] and Air-Octor [16], with a single segment mimicking a trunk (Figure 2(a)). The soft gripper developed in the shape of a cone [18] is an example of the single-segmented robot. The soft manipulator [17] is bisegmented, and the granular robots [20] are the additional models with dual and triple segments (Figure 2(b)). As an advancement, the research on the second-generation robots consists of trunks with a backbone and multiple discs, with the increased complexity of actuation and manipulation. These trunks consist of multiple segments with dual actuation, i.e., electric motor and pneumatic [21-28]. In the current research scenario, the third-generation continuum robot, which is known as the bionic handling assistant (BHA) model developed by Festo [29-31], has entered the production environment. This is an advanced prototype that is constructed using the concepts of lightweight design and possesses the capability to operate with increased flexibility. This model consists of three segments with variable curvatures supported by tendons and with a weight of $1.8 \mathrm{~kg}$. The structure and components of the BHA are shown in Figure 2(c), along with the three-fingered end effectors to grasp the objects.

Continuum models inspired by the spine of the mammal [32-55] and snake [56-71] are the most common examples of the multidisc biomodels with single or multiple segments that consist of a structured alignment of discs, as shown in Figure 3(a). Spine structures can possess only bending 
TABle 2: The classification of continuum models.

\begin{tabular}{|c|c|c|c|c|}
\hline Robot structure & Description & Application & Advantage & $\begin{array}{l}\text { References } \\
\text { (examples) }\end{array}$ \\
\hline Single segment & $\begin{array}{l}\text { Robot body consists of a single backbone-like structure with } \\
\text { limited constant curvature freedom of motion. }\end{array}$ & Cleaning & Simple structure & $\begin{array}{c}\text { Elephant: [15] } \\
\text { Human arm: } \\
\text { [156] } \\
\text { Octopus: [76] } \\
\text { Vine: [179] } \\
\text { Elephant: [14] }\end{array}$ \\
\hline Multisegment & $\begin{array}{l}\text { Robot body consists of multiple segments, each with the } \\
\text { freedom to move as a single element structure, but independent } \\
\text { of other elements. }\end{array}$ & Inspection & $\begin{array}{l}\text { Connected } \\
\text { control }\end{array}$ & $\begin{array}{c}\text { Human arm: [51] } \\
\text { Vine: [173] } \\
\text { Tongue and tail: } \\
\text { [183] } \\
\text { Snake: }[70]\end{array}$ \\
\hline $\begin{array}{l}\text { Single segment- } \\
\text { multidisc }\end{array}$ & $\begin{array}{l}\text { The robot body is composed of multiple discs of the same or } \\
\text { varying radii arranged equidistant from each other, along with } \\
\text { a backbone structure that is a single segment. }\end{array}$ & $\begin{array}{l}\text { Medical } \\
\text { surgery }\end{array}$ & Maneuverability & $\begin{array}{c}\text { Elephant: [28] } \\
\text { Mammalian } \\
\text { spine: }[35] \\
\text { Snake: }[32] \\
\text { Tentacle: [87] } \\
\text { Tongue and tail: } \\
\text { [182] } \\
\text { Vine: }[166]\end{array}$ \\
\hline $\begin{array}{l}\text { Multi segment- } \\
\text { multidisc }\end{array}$ & $\begin{array}{l}\text { The robot body is composed of multiple discs of the same or } \\
\text { varying radii arranged equidistant from each other, along with } \\
\text { a backbone structure that is of multiple segments. }\end{array}$ & Mobility & Multipurpose & $\begin{array}{c}\text { Elephant: [24] } \\
\text { Mammalian } \\
\text { spine: [42] } \\
\text { Snake: [63] } \\
\text { Tentacle: [91] } \\
\text { Human arm: } \\
\text { [157] }\end{array}$ \\
\hline $\begin{array}{l}\text { Continuous } \\
\text { structure }\end{array}$ & $\begin{array}{l}\text { Robot body consists of multiple fibers braided together. The } \\
\text { fiber ends are connected to cables that can be individually } \\
\text { wound up/down from a pulley. }\end{array}$ & Manipulation & Flexibility & $\begin{array}{c}\text { Vine: [180] } \\
\text { Snake: [68] } \\
\text { Octopus: [72] } \\
\text { Tentacle: [90] } \\
\text { Biological vine: } \\
\text { [161] } \\
\text { Human arm: } \\
\text { [149] } \\
\text { Plant: [181] }\end{array}$ \\
\hline
\end{tabular}
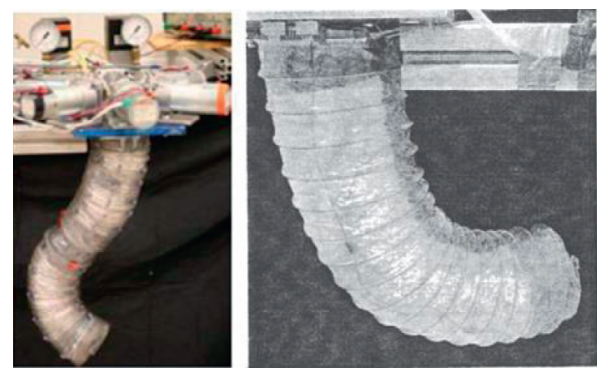

(a)
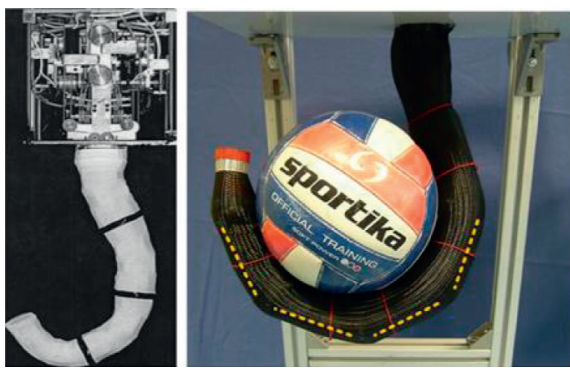

(b)

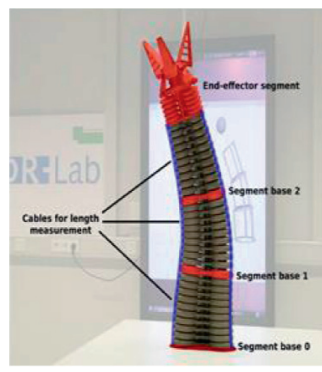

(c)

FIGURE 2: Single-segmented [14, 16] (a), multisegmented [19, 28] (b), and continuum robots [29] (c)-elephant trunk inspired.

movements with limited angular constraints and with a fixed base, and snakes belong to the class of reptiles that have the capability to elongate their bodies without limbs to grasp or manipulate objects with precision in a confined space. The single-segment-multidisc models, spine [32-42] and snake [56-62], are generally made up of circular metal structures equidistantly placed along the backbone. The discs are magnetically polarized so that the distance between the discs remains constant and can take up the shape of constant curvature to achieve the hemispherical surface of the end effector. These discs are either made up of steel or hard polyamide material. The multisegmented models of the 

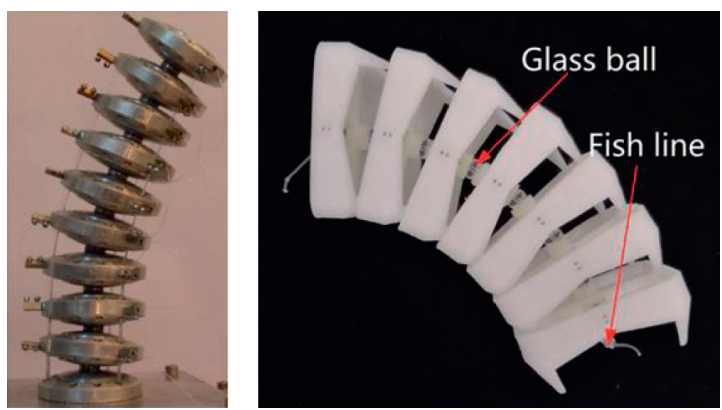

(a)
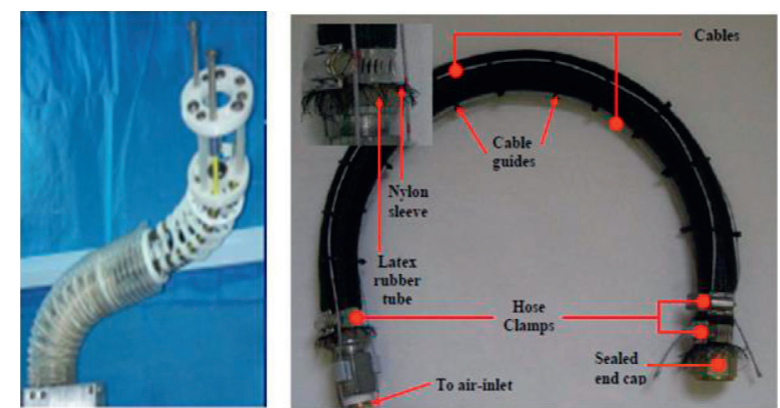

(b)

Figure 3: Single-segmented and multidisc continuum robots: (a) spine [40,53] and (b) snake inspired [65, 69].

spine [43-55] are aligned with metal intervertebral discs aligned at a constant distance that provide nonlinear damping characteristics, and snake [63-67] is constructed with cylindrical tubes connected with joints with rotational and translational degrees of freedom and mostly used for inspection through holes, as shown in Figure 3(b). To reach the model of a continuum structure, snake models [68-71] are developed that are made up of braided or shape memory alloy materials and consist of dual actuation, i.e., are cable or pneumatic driven.

Octopus- and tentacle-inspired [84-131] models are mostly single-segmented examples. Octopus is a class of cephalopods whose structure is symmetric along the axis bisecting its two eyes, whereas tentacle is a long-elongated organ (example of tentacle inspired robot [121]) present in many invertebrates that usually occurs in pairs. The legs of the octopus have the unique capability to perform locomotion and manipulation [188], and tentacles are tiny thread-like structures that are used for grasping and feeding along with sensory reception, which proves the easy choice for robotics enthusiasts to develop continuum structures that are singlesegmented (Figure 4(a)). Laschi et al. [72-76] are one of the early researchers who developed continuum robot models built with longitudinal and transverse actuators using silicone and braided fiber as materials (Figure 3(b)). To develop a realistic case scenario, Guglielmino et al. [78] had obtained consent with respect to EU regulations to perform morphometric analysis on several anaesthetized octopuses with the support of a marine biologist. This experiment provided detailed information regarding the structure of octopus limbs, which assisted in developing prototypes [79-83] using shape memory alloys (current sensitive) and fluid actuators mimicking the animal behavior.

The human arm is the most complex biomodel, and researchers have developed models that augment safety in manipulation applications with respect to physical human interaction. All such robot structures can be categorized into two models, i.e., multifingered hand robots (Figure 5) and multijoint extendable arms (Table 3). All the multifingered hand robots [132-146] were developed to have a similar structure, with a metal or plastic base and fingers made up of hardened polyamide material. The human arm robots $[147-159,189]$ are designed with multijoints and a unique end effector and are categorized based on the application perspective, as shown in Table 3.

All the biomodels discussed in the previous sections are animal-inspired robots. In this section, the continuum robots that are vine and plant inspired are explored. The hyperflexible manipulator (HFM) developed by Suzuki et al. [160] is one of the best examples of vine inspired, consisting of multiple underactuated links and nonelastic passive joints resembling a rope used for better casting and winding along the object. The primary application of vineinspired robots is in the field of space and planetary exploration. Scientists at NASA, Mehling et al. [161] and Tonapi et al. [163], developed a tendril robot (Figure 6(a)) and a robotic manipulator for minimally invasive inspection along with manipulation for space operations [160-170]. The tendril robot consists of three subsystems with nine motors of actuation, body mechanism, and avionics, as shown in Figure 6(a) [161]. In order to utilize the capability of extending their segments longitudinally, the class of continuum robots [175-181] inspired by biological plants was developed. Their structure is pneumatically actuated [181], which controls the longitudinal height and is made up of a polyamide structure that is widely used in deploying antennas [177-179] or in operations that require a periscope $[175,180]$. To enhance the application areas of vine robots, researchers found advantages of using these structures [171-174] in further applications, including autonomous refueling, exploration [174], water spraying [171], aircraft fueling [173], body inspection [170, 176], and engine repair [172], as shown in Figure 6(b).

The final categorization of the continuum robots is the structure inspired by the tail and chameleon tongue of an animal. The chameleon tongue-inspired robot (Figure 7(b)) [183] consists of a mechanism that can accommodate the principle of elastic energy storage and release, which can elongate to 1.5 times its body length and can exert a force of $500 \mathrm{~m} / \mathrm{s}^{2}$. The tail (Figure 7(a)) [182] on the structures has very few engineering applications, which are envisioned for use on board a mobile robot to provide a means separate from the locomotion mechanism (e.g., legs or wheels) to generate external forces and moments to stabilize and/or maneuver the robot. 


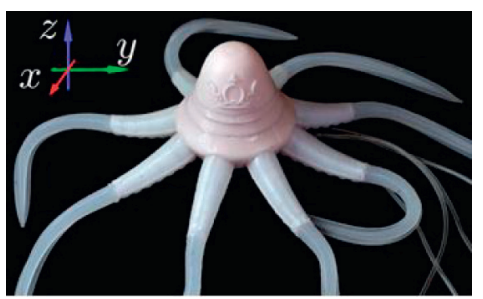

(a)

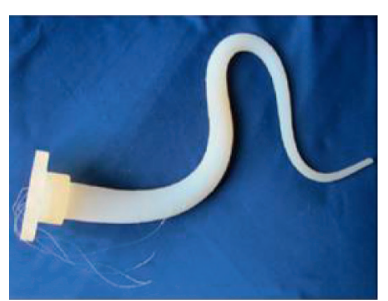

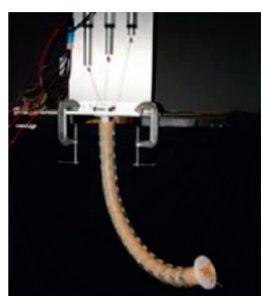

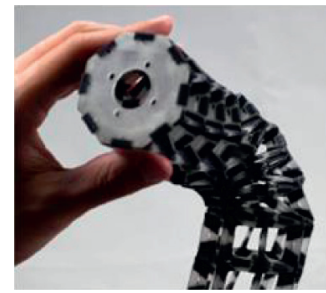

(b)

FIgURE 4: Continuum robots: octopus leg [77] (a) and tentacle inspired [90, 101] (b).

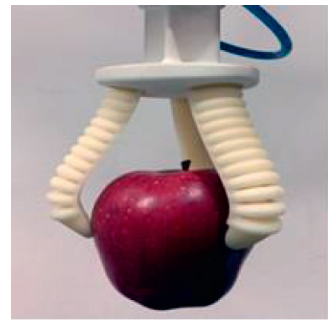

(a)

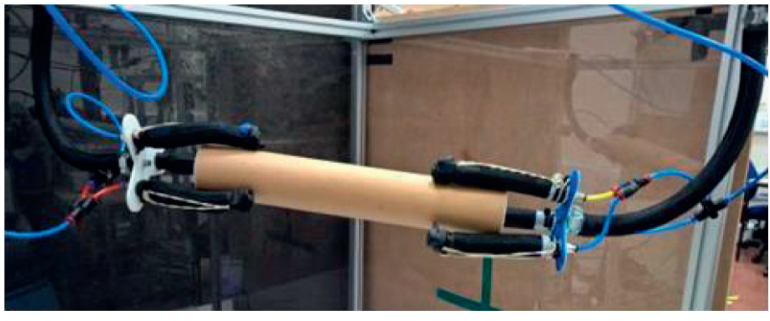

(b)

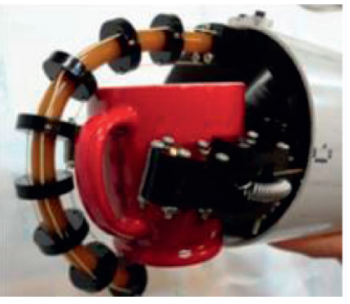

(c)

FIgURe 5: Continuum robots: human arm inspired [135, 151].

TABLE 3: Human hand-inspired continuum model applications.

Inflatable arm/safe human interaction [147]

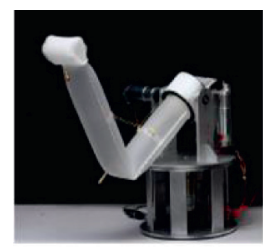

Hand-held arm/cleaning and drilling [151]

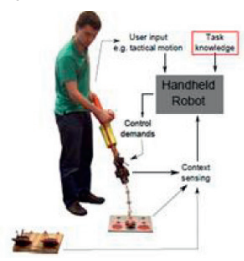

1

Collaborative robot/coordination [158]

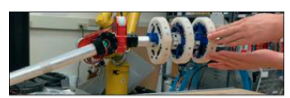

Exoskeleton/support for heavy lifting [148]

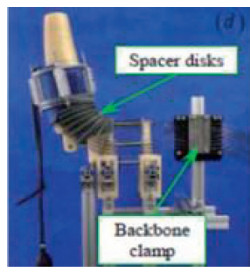

Anthropomorphic bot/games and recreation [152]

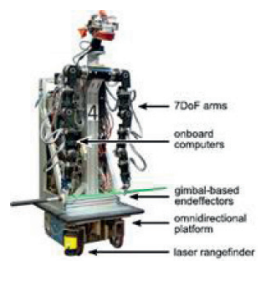

2
Extendable arm/inspection and penetration [149]

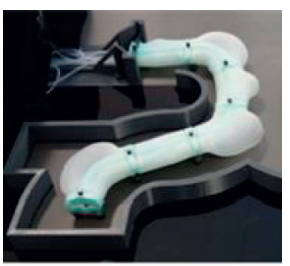

Inflatable joint robot/ brittle material

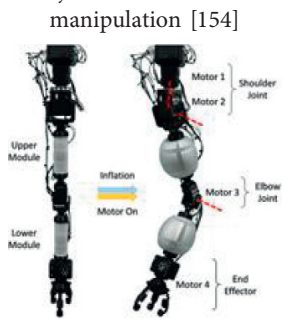

NASA - planetary arm/space exploration [155]

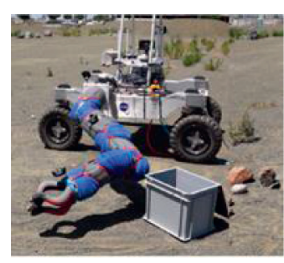

Reconfigurable robot/rehabilitation assistance [156]

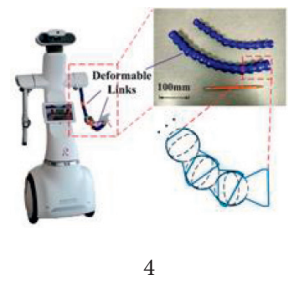

Robo-glove/ grasping and manipulation [189]

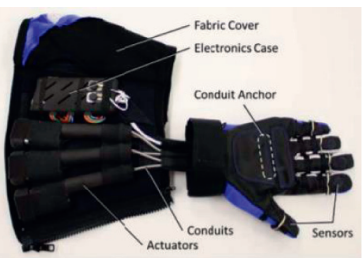

Arm robot/grasping and holding [157]

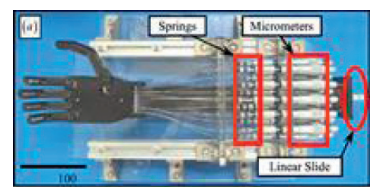

Fabric-based arm/lightweight model [153]

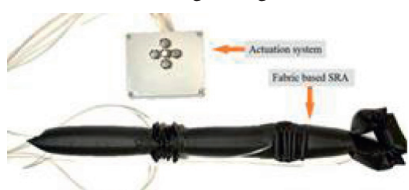




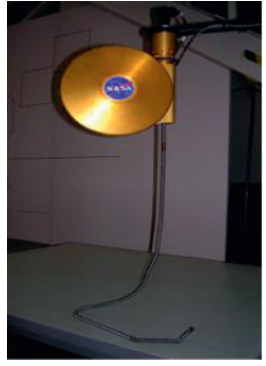

(a)
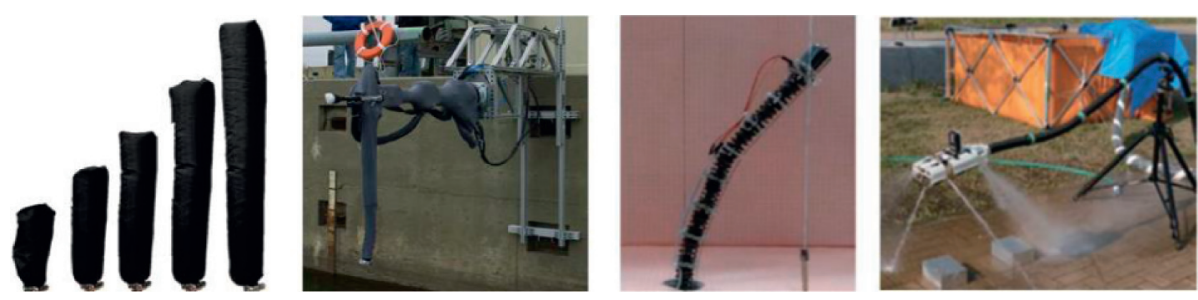

(b)

FIGURE 6: Continuum robots: (a) vine $[163,178]$ and (b) plant inspired $[171,181]$.

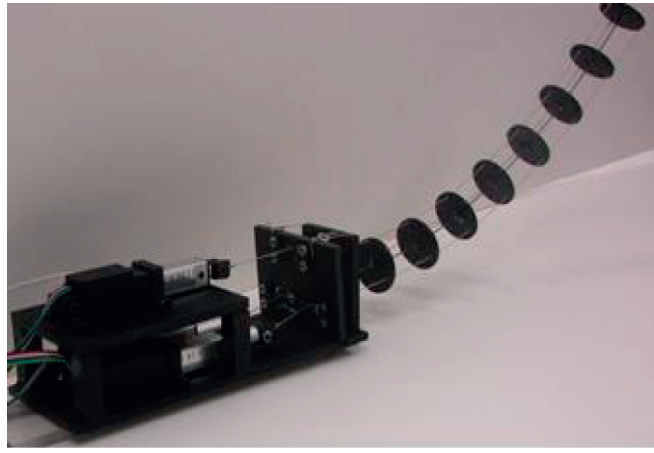

(a)

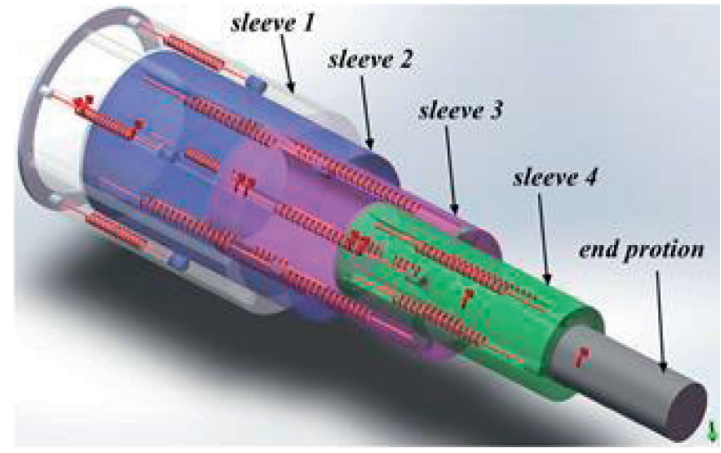

(b)

FIGURE 7: Continuum robots: (a) tail [182] and (b) tongue [183] inspired.

Table 4: Polyamide material applications-continuum robot models.

\begin{tabular}{lcc}
\hline Polyamide material & Advantages & Robots (examples) \\
\hline $\begin{array}{l}\text { Polycarbonate } \\
\text { Polyamide-rubber } \\
\text { amalgamation }\end{array}$ & Durability, high impact, and low scratch resistance & Exploration robot [174] \\
$\begin{array}{l}\text { Polyurethane } \\
\text { Polyethene }\end{array}$ & Contraction and elongation & Artificial muscles [190] \\
$\begin{array}{l}\text { Polyamide-carbon } \\
\text { amalgamation }\end{array}$ & Lightweight design, temperature resistance & Engine repair robot [172] \\
Periscope and antenna robot \\
\hline
\end{tabular}

TABLE 5: Other material applications-continuum robot models.

\begin{tabular}{|c|c|c|}
\hline Other materials & Advantages & Robots (examples) \\
\hline Silicone & $\begin{array}{l}\text { Abundantly available with lost cost and provides extraneous flexibility; resistant } \\
\text { to abrasion, acidic, and basic ambience }\end{array}$ & Octopus arm $[72,73]$ \\
\hline Nitinol & $\begin{array}{l}\text { Inert material with maximum nickel composition, very dexterous, and } \\
\text { manipulative }\end{array}$ & $\begin{array}{l}\text { Vine-inspired robot [163], spine } \\
\text { robot [34] }\end{array}$ \\
\hline Aluminum & Low cost and lightweight & Hybrid robots-multidisc [191] \\
\hline Braided surface & High strength and lightweight & $\begin{array}{l}\text { Dual-segmented [34] elephant trunk } \\
\text { [17] }\end{array}$ \\
\hline $\begin{array}{l}\text { Shape memory } \\
\text { alloy }\end{array}$ & Strong and corrosion resistance & $\begin{array}{l}\text { Octopus limbs [79-83], elephant } \\
\text { trunk }[21,23]\end{array}$ \\
\hline
\end{tabular}

2.2. Material. The material of choice for bioinspired continuum robots is polyamide-a polymerized molecular chain made of nylon braided blend or carbon amalgamation (e.g., borax and vinyl alcohol) whose strength, elasticity, and flexibility can be customized per the application. Other materials used in construction of continuum robots are 
TABLE 6: Braided and fiber material for the pneumatic actuator.

\begin{tabular}{lccc}
\hline PMA & Description & Usage & Advantage \\
\hline $\begin{array}{l}\text { Braided } \\
\text { material } \\
{[192-207]}\end{array}$ & $\begin{array}{c}\text { Produced using weaving and knitting } \\
\text { methodology. }\end{array}$ & $\begin{array}{c}\text { Mostly used in the } \\
\text { manufacturing industry and } \\
\text { lightweight machine operations. }\end{array}$ & $\begin{array}{c}\text { This structure possesses the useful } \\
\text { property of elongation and } \\
\text { compression with respect to the input } \\
\text { air pressure. }\end{array}$ \\
$\begin{array}{l}\text { Fiber material } \\
{[208-211]}\end{array}$ & $\begin{array}{c}\text { Two kinds of fibers are currently used in the } \\
\text { industry, depending on the application, } \\
\text { produced by plants, animals, and geological } \\
\text { processes. }\end{array}$ & $\begin{array}{c}\text { Used in every technical } \\
\text { engineering application. Suitable } \\
\text { for heavyweight operation. }\end{array}$ & $\begin{array}{c}\text { Possesses excellent twisting and } \\
\text { longitudinal strength. }\end{array}$ \\
\hline
\end{tabular}
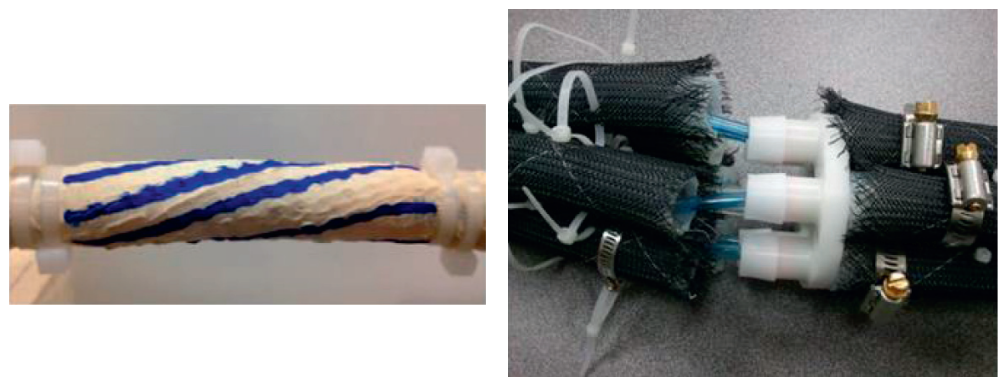

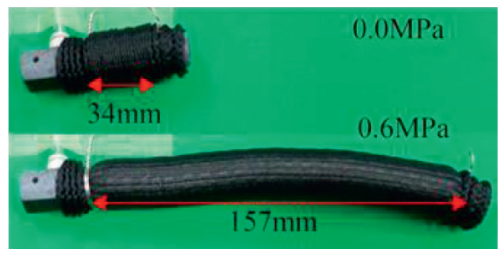

Figure 8: Pneumatic artificial muscle-fiber material and braided structure [206-209].

TABLE 7: Electric motors as force actuators.

Electrical motors

Direct current motors

Servo electric motors

Stepper electric motors
Application robots (examples)

Tendril robot, hyperflexible/dexterous manipulator [161, 165, 169] Braided octopus arm, silicone arm robot, multidisc robot [72] Multidisc tentacle arm [87, 222]

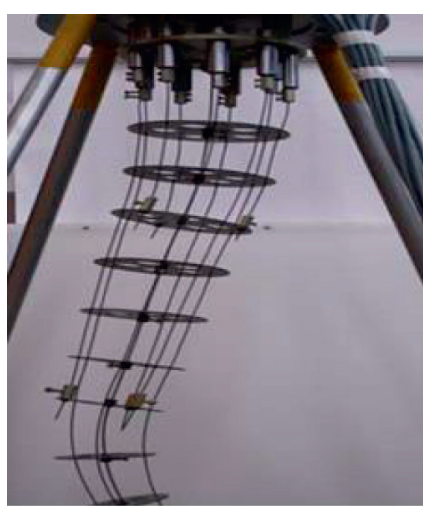

(a)

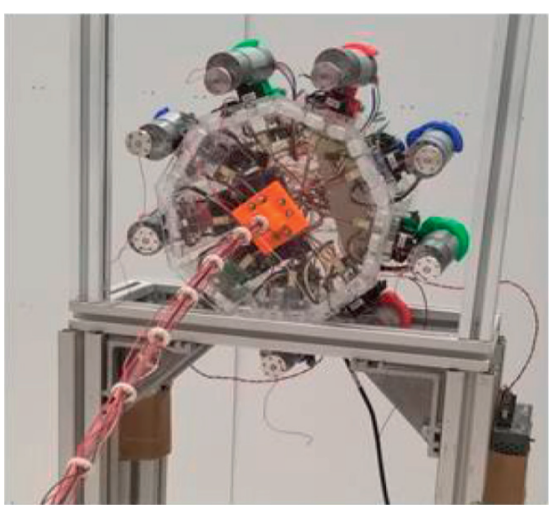

(b)

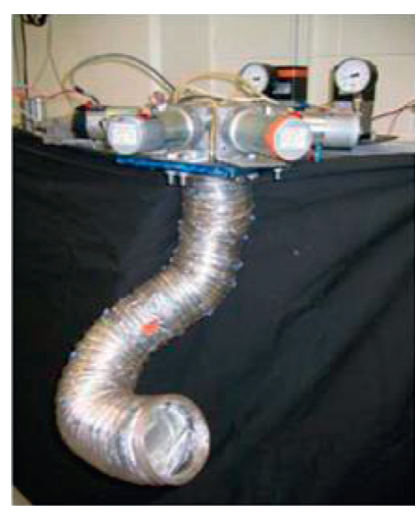

(c)

Figure 9: Drive mechanism: (a) tendon alignment [87], (b) electric motor [162]—tendon, and (c) pneumatic [16]—nontendon.

TABLe 8: Drive mechanisms.

\begin{tabular}{|c|c|c|c|c|}
\hline Drive mechanism & orce actuation & Advantages & Disadvantages & Material \\
\hline $\begin{array}{l}\text { Tendon driven } \\
\text { [32-71] }\end{array}$ & $\begin{array}{l}\text { Electric or } \\
\text { pneumatic }\end{array}$ & $\begin{array}{l}\text { Simple calculation and low error in } \\
\text { estimating the end-effector position }\end{array}$ & $\mathrm{Co}$ & $\begin{array}{l}\text { Polyamide } \\
\text { structure }\end{array}$ \\
\hline $\begin{array}{l}\text { Nontendon driven } \\
\text { [192-211] }\end{array}$ & $\begin{array}{l}\text { Pneumatic } \\
\text { (PMA) }\end{array}$ & $\begin{array}{c}\text { Simple body structure to contract and } \\
\text { elongate }\end{array}$ & $\begin{array}{l}\text { Complex calculation and high error in } \\
\text { estimating the end-effector position }\end{array}$ & $\begin{array}{l}\text { Braided and } \\
\text { fiber }\end{array}$ \\
\hline
\end{tabular}


TABle 9: Types of sensors and their applications.

\begin{tabular}{|c|c|c|}
\hline Application & Sensor type & Description \\
\hline \multirow[t]{2}{*}{ Force actuation } & Pressure sensor & $\begin{array}{l}\text { The pressure sensor provides the feedback of the air pressure applied by the pneumatic } \\
\text { actuator [226]. }\end{array}$ \\
\hline & Torque sensor & The torque output by the electrical motor is measured by the torque sensor [222]. \\
\hline \multirow{6}{*}{$\begin{array}{l}\text { Robot body shape } \\
\text { estimation }\end{array}$} & Potentiometer & $\begin{array}{l}\text { Potentiometers consist of sliding or rotating contacts, which are installed to know the } \\
\text { length of each segment of the continuum robot based on the change in the voltage [224]. }\end{array}$ \\
\hline & Image camera & $\begin{array}{l}\text { An image camera consists of a high-resolution lens with a maximum frame rate to } \\
\text { estimate the shape in real time using image processing and machine vision techniques. } \\
\text { Common examples include Dalsa camera, Kinect camera, XCD X710 digital camera, AK } \\
4 \text {, and AK7 }[229,230,232-234] .\end{array}$ \\
\hline & Resistor shape sensor & $\begin{array}{l}\text { The resistive sensor is sensitive to twisting or elongation and changes its resistance } \\
\text { proportional to the deflection }[237,240] .\end{array}$ \\
\hline & Fiber Bragg gratings & $\begin{array}{l}\text { FBG are similar to optical sensors. These sensors are mostly used to obtain the curvature } \\
\text { of the robot body in the static and dynamic mode by obtaining the strain information at } \\
\text { different locations along the structure }[223,227] .\end{array}$ \\
\hline & Dielectric elastomer & $\begin{array}{l}\text { This sensor is embedded into the actuators with distributed actuation points that could } \\
\text { cover soft bodies. It is highly flexible and can be adaptable to soft structures to obtain } \\
\text { information regarding surface deflections. The examples used in robotics include DEAs, } \\
\text { VHB } 4910[236,238] \text {. }\end{array}$ \\
\hline & $\begin{array}{l}\text { Magnetoresistive } \\
\text { sensor }\end{array}$ & $\begin{array}{l}\text { The magnetoresistive sensor is mostly used to detect any kind of geometrical deflection } \\
\text { or thermal sensitivity and provides an output based on the desired parameters, e.g., } \\
\text { contraction of a bundled actuator [225]. }\end{array}$ \\
\hline \multirow{4}{*}{$\begin{array}{l}\text { End-effector position } \\
\text { estimation }\end{array}$} & $\begin{array}{l}\text { 3D electromagnetic } \\
\text { sensor }\end{array}$ & $\begin{array}{l}\text { These sensors are generic sensors that are electromagnetic wave emitters and are } \\
\text { installed onto the shape of the robot and emit the signals in regular intervals captured by } \\
\text { receivers [192]. }\end{array}$ \\
\hline & Infrared sensor & $\begin{array}{l}\text { An infrared sensor is less accurate when compared to other electromagnetic sensors } \\
\text { because of temperature sensitivity. It emits radiation to estimate the relative coordinate } \\
\text { position, e.g., MicroScribe MX [180]. }\end{array}$ \\
\hline & Optical sensor & $\begin{array}{l}\text { The optical sensor is the most accurate sensor for estimating the coordinate positions of } \\
\text { any robotic component. It is used for modulating the intensity of light from the specific } \\
\text { position to estimate the relative distance, which can also be used to estimate the shape of } \\
\text { the robot, e.g., Micron Tracker SX60 [235]. }\end{array}$ \\
\hline & Laser sensor & $\begin{array}{l}\text { The laser sensor is a type of optical sensor that is capable of projecting electromagnetic } \\
\text { radiation to a specific point on the end effector to obtain the relative position } \\
\text { coordinates, e.g., FARO Edge laser [34]. }\end{array}$ \\
\hline
\end{tabular}

silicone, nitinol, aluminum, braided fabrics, and shape memory alloys. Tables 4 and 5 provide a taxonomy of various materials used in the construction of continuum robots.

\section{Force Actuator}

Force actuator refers to the component of a continuum robot that drives its physical movement. The most common actuators used within continuum robots are either pneumatic or electrical motors. Although not as common, other actuators such as hydraulic, twisted polymer, thermal, or magnetic are also used in fewer applications.

3.1. Pneumatic Actuator. Pneumatic actuators [46, 190-220] are the most commonly used kind in continuum robots because they are less complex and are low cost. The drive is produced by forced air injected or withdrawn from the body of the continuum structure (Table 6). These were first developed under the name of McKibben actuators arranged symmetrically along the central axis of the robot's body with flexible pairs on opposite sides pressurized by one solenoid valve, which controls the volume and direction of the airflow using a pressure sensor. The dissection of the artificial pneumatic muscle actuator (PMA), along with the body modeled using fiber [209] or braided [206] material, is shown in Figure 8. PMA provides a good balance of actuation performance and power-to-weight ratio, the description of which is significantly explained in the survey [221]. Further examples of continuum robotic structures developed using the PMA are shown in [46, 190, 191, 212-220].

3.2. Electrical Motors. The tendon-driven continuum manipulators are the first structures developed with bending segments of adjustable length. These structures assist the body to generate curves with variable curvature radii, which augments the efficiency of grasping. Researchers examined the properties of tentacle-like continuum robots and arranged tendons in pairs that are actuated by motors. Almost every structure with a built-in tendon is actuated by electric motors (direct current, servo, or stepper motors) (Table 7).

3.3. Drive Mechanisms. In general, the articles referenced in this paper do not discuss the underlying drive mechanism in 
detail as they focus on the novelty of their continuum robots with respect to design elements and mobility. The drive mechanism of the continuum robot is generally categorized into either tendon or nontendon driven (Figure 9). These mechanisms have common functionality of manipulation along with defining the body shape and the end-effector position of the robot (Table 8).

\section{Additional Design Elements}

In this section, we briefly outline some additional information with respect to dual actuation and sensors. Some of the primary continuum robotic structures have a built-in dual actuator (pneumatic and electrical motor), which provides the additional advantage of increased actuation capability and reduced errors in movement, i.e., manipulating the end effector to the desired location, obtaining the desired shape of the robot with increased degrees of freedom, and so on. The bionic arm is the latest example that utilizes the advantage of the dual actuator mechanism. One of the main challenges for developing continuum robots for manipulation is estimating the required amount of actuation, the shape of the robot, and the position of the end effector at an instant in real time. The information regarding these parameters can be obtained using various sensors inbuilt in the system, which can hugely assist in the robotic control to achieve the defined task. Although the control techniques are out of the scope of this survey, we briefly mention different kinds of sensors [222-240] used in the current research scenario. Sensors in the field of soft robots are broadly classified into three categories based on their application, i.e., force actuation, shape, and end-effector position estimation. Among the various sensors adopted, the optical sensor proves the best because of its lower error tolerance and its ability to be utilized for the dual purpose of shape and end-effector position estimation (Table 9).

\section{Conclusion}

Innovation and creativity are two of the essential ingredients in the evolution of robotics and automation, which started a century ago. Developing continuum robots that mimic biologically inspired species began more recently-two decades ago. Here, the natural design elements present in humans, animals, birds, plants, etc. provide a template for scientific progress. As a result, continuum bioinspired robots have been investigated for numerous applications.

In this literature survey, we covered numerous bioinspired continuum robot models that have been developed and provided a framework for examining them, namely, bioinspiration, mechanical design, construction material, and force actuation. The progress made in continuum robotics is very compelling and provides a great foundation to tackle the major challenges required for their use in manufacturing-low cost, reduced cycle-time, and safe human interaction.

\section{Conflicts of Interest}

The authors declare that they have no conflicts of interest.

\section{Acknowledgments}

The authors thank Prof. Dr. Alireza Mohammadi, University of Michigan, USA, for participating in initial discussions and William J. Clifford, General Motors Inc., Warren Technical Center, Michigan, USA, for supporting this research.

\section{References}

[1] B. Singh, N. Sellappan, and P. Kumaradhas, "Evolution of industrial robots and their applications," International Journal of Emerging Technology and Advanced Engineering, vol. 3, no. 5, pp. 763-768, 2013.

[2] H. G. Sage, M. F. De Mathelin, and E. Ostertag, "Robust control of robot manipulators: a survey," International Journal of Control, vol. 72, no. 16, pp. 1498-1522, 1999.

[3] M. A. K. Bahrin, M. F. Othman, N. N. Azli, and M. F. Talib, "Industry 4.0: a review on industrial automation and robotics," Jurnal Teknologi, vol. 78, no. 6-13, pp. 137-143, 2016.

[4] P. K. Singh and C. M. Krishna, "Continuum arm robotic manipulator: a review," Universal Journal of Mechanical Engineering, vol. 2, no. 6, pp. 193-198, 2014.

[5] V. Villani, F. Pini, F. Leali, and C. Secchi, "Survey on humanrobot collaboration in industrial settings: safety, intuitive interfaces and applications," Mechatronics, vol. 55, pp. 248-266, 2018.

[6] S. H. Sadati, S. E. Naghibi, A. Shiva, I. D. Walker, K. Althoefer, and T. Nanayakkara, "Mechanics of continuum manipulators, a comparative study of five methods with experiments," in Proceedings of the Annual Conference towards Autonomous Robotic Systems, Springer, Guildford, UK, pp. 686-702, July 2017.

[7] L. S. Cowan and I. D. Walker, "The importance of continuous and discrete elements in continuum robots," International Journal of Advanced Robotic Systems, vol. 10, no. 3, p. 165, 2013.

[8] G. Robinson and J. B. C. Davies, "Continuum robots-a state of the art," in Proceedings of the IEEE International Conference on Robotics and Automation (Cat. No. 99CH36288C), vol. 4, pp. 2849-2854, Detroit, MI, USA, May 1999.

[9] J. K. Hopkins, B. W. Spranklin, and S. K. Gupta, "A survey of snake-inspired robot designs," Bioinspiration \& Biomimetics, vol. 4, no. 2, Article ID 021001, 2009.

[10] J. M. M. Tur and W. Garthwaite, "Robotic devices for water main in-pipe inspection: a survey," Journal of Field Robotics, vol. 4, no. 27, pp. 491-508, 2010.

[11] B. Siciliano and O. Khatib, "Humanoid robots: historical perspective, overview, and scope," in Humanoid Robotics: A Reference, pp. 3-8, Springer, Dordrecht, Netherlands, 2019.

[12] J. Burgner-Kahrs, D. C. Rucker, and H. Choset, "Continuum robots for medical applications: a survey," IEEE Transactions on Robotics, vol. 31, no. 6, pp. 1261-1280, 2015.

[13] D. Trivedi, C. D. Rahn, W. M. Kier, and I. D. Walker, "Soft robotics: biological inspiration, state of the art, and future research," Applied Bionics and Biomechanics, vol. 5, no. 3, pp. 99-117, 2008.

[14] B. A. Jones and I. D. Walker, "Practical kinematics for realtime implementation of continuum robots," IEEE Transactions on Robotics, vol. 22, no. 6, pp. 1087-1099, 2006. 
[15] B. A. Jones, W. McMahan, and I. Walker, "Design and analysis of a novel pneumatic manipulator," IFAC Proceedings Volumes, vol. 37, no. 14, pp. 687-692, 2004.

[16] W. McMahan, B. A. Jones, and I. D. Walker, "Design and implementation of a multi-section continuum robot: airoctor," in Proceedings of the 2005 IEEE/RSJ International Conference on Intelligent Robots and Systems, pp. 2578-2585, Edmonton Canada, August 2005.

[17] M. Csencsits, B. A. Jones, W. McMahan, V. Iyengar, and I. D. Walker, "User interfaces for continuum robot arms," in Proceedings of the 2005 IEEE/RSJ International Conference on Intelligent Robots and Systems, pp. 3123-3130, Edmonton Canada, August 2005.

[18] M. E. Giannaccini, I. Georgilas, I. Horsfield et al., "A variable compliance, soft gripper," Autonomous Robots, vol. 36, no. 12, pp. 93-107, 2014.

[19] R. Kang, E. Guglielmino, L. Zullo, D. T. Branson, I. Godage, and D. G. Caldwell, "Embodiment design of soft continuum robots," Advances in Mechanical Engineering, vol. 8, no. 4, p. 1687814016643302, 2016.

[20] S. M. Z. Sayyadan, F. Gharib, and A. Garakan, "Granular jamming manipulator filled with new organic materials," in Proceedings of the 2017 22nd International Conference on Methods and Models in Automation and Robotics (MMAR), pp. 396-401, Dzyzdroje, Poland, August 2017.

[21] R. Luo, T. Wang, Z. Shi, and J. Tian, "Design and kinematic analysis of an elephant-trunk-like robot with shape memory alloy actuators," in Proceedings of the 2017 IEEE 2nd Advanced Information Technology, Electronic and Automation Control Conference (IAEAC), pp. 157-161, Chongqing, China, March 2017.

[22] Y. Jin, Y. Wang, X. Chen et al., "Model-less feedback control for soft manipulators," in Proceedings of the 2017 IEEE/RSJ International Conference on Intelligent Robots and Systems (IROS), pp. 2916-2922, Vancouver, Canada, September 2017.

[23] L. Zhang, M. Xu, and H. Yang, "Research on soft manipulator actuated by shape memory alloy (SMA) springs," in Proceedings of the 2017 IEEE International Conference on Real-Time Computing and Robotics (RCAR), pp. 74-78, Okinawa, Japan, July 2017.

[24] T. Yukisawa, S. Nishikawa, R. Niiyama, Y. Kawahara, and Y. Kuniyoshi, "Ceiling continuum arm with extensible pneumatic actuators for desktop workspace," in Proceedings of the 2018 IEEE International Conference on Soft Robotics (RoboSoft), pp. 196-201, Livorno, Italy, April 2018.

[25] T. G. Thuruthel, E. Falotico, F. Renda, and C. Laschi, "Model-based reinforcement learning for closed-loop dynamic control of soft robotic manipulators," IEEE Transactions on Robotics, vol. 35, no. 1, pp. 124-134, 2018.

[26] A. Yeshmukhametov, K. Koganezawa, and Y. Yamamoto, "Design and kinematics of cable-driven continuum robot arm with universal joint backbone," in Proceedings of the 2018 IEEE International Conference on Robotics and Biomimetics (ROBIO), pp. 2444-2449, Kuala Lumpur, Malaysia, December 2018.

[27] M. W. Hannan and I. D. Walker, "). Analysis and initial experiments for a novel elephant's trunk robot," in Proceedings of the 2000 IEEE/RSJ International Conference on Intelligent Robots and Systems (IROS 2000) (Cat. No. 00CH37113), vol. 1, pp. 330-337, Takamatsu, Japan, November 2000.

[28] M. W. Hannan and I. D. Walker, "The elephant trunk manipulator, design and implementation," in Proceedings of the 2001 IEEE/ASME international conference on advanced intelligent mechatronics. (Cat. No. 01TH8556), vol. 1, pp. 14-19, Como, Italy, July 2001.

[29] C. Escande, P. M. Pathak, R. Merzouki, and V. Coelen, "Modelling of multisection bionic manipulator: application to robotino XT," in Proceedings of the 2011 IEEE International Conference on Robotics and Biomimetics, pp. 92-97, Karon Beach, Thailand, December 2011.

[30] M. Rolf and J. J. Steil, "Efficient exploratory learning of inverse kinematics on a bionic elephant trunk," IEEE Transactions on Neural Networks and Learning Systems, vol. 25, no. 6, pp. 1147-1160, 2013.

[31] X. You, Y. Zhang, X. Chen et al., "Model-free control for soft manipulators based on reinforcement learning," in Proceedings of the 2017 IEEE/RSJ International Conference on Intelligent Robots and Systems (IROS), pp. 2909-2915, Vancouver, Canada, September 2017.

[32] M. Neumann and J. Burgner-Kahrs, "Considerations for follow-the-leader motion of extensible tendon-driven continuum robots," in Proceedings of the 2017 IEEE International Conference on Robotics and Automation (ICRA), pp. 917-923, Singapore, May-June 2016.

[33] A. Parvaresh, S. A. Moosavi, and S. A. A. Moosavian, "Identification and position control of a continuum robotic arm," in Proceedings of the 2017 5th RSI International Conference on Robotics and Mechatronics (ICRoM), pp. 310-315, Tehran, Iran, October 2017.

[34] J. Starke, E. Amanov, M. T. Chikhaoui, and J. BurgnerKahrs, "On the merits of helical tendon routing in continuum robots," in Proceedings of the 2017 IEEE/RSJ International Conference on Intelligent Robots and Systems (IROS), pp. 6470-6476, Vancouver, Canada, September 2017.

[35] I. P. Georgilas and V. D. Tourassis, "Ermis-a novel biologically inspired flexible robotic mechanism for industrial applications," in Proceedings of the IEEE/ASME International Conference on Advanced Intelligent Mechatronics, pp. 1504-1509, Singapore, July 2009.

[36] Y. Li and Y. Chen, "The ultimate hyper redundant robotic arm based on omnidirectional joints," in Proceedings of the 2015 IEEE International Conference on Mechatronics and Automation (ICMA), pp. 1840-1845, Beijing, China, August 2015.

[37] G. Runge, S. Zellmer, T. Preller, G. Garnweitner, and A. Raatz, "Actuation principles for the bioinspired soft robotic manipulator spineman," in Proceedings of the 2015 IEEE International Conference on Robotics and Biomimetics (ROBIO), pp. 1329-1336, Kuala Lumpur, Malaysia, December 2015.

[38] T. Zhang, B. Li, D. Wang, L. Ma, and X. Zhao, "Kinematic analysis and its applications of a novel spherical parallel manipulator," in Proceedings of the 2016 IEEE International Conference on Robotics and Biomimetics (ROBIO), pp. 1309-1312, Qingdao, China, December 2016.

[39] S. Huang, D. Meng, Y. She, X. Wang, B. Liang, and B. Yuan, "Statics of continuum space manipulators with nonconstant curvature via pseudorigid-body $3 \mathrm{R}$ model," IEEE Access, vol. 6, pp. 70854-70865, 2018.

[40] J. Liu, T. Jin, L. Li et al., "Research on bending and torsion properties of bionic square continuum robot," in Proceedings of the 2018 IEEE International Conference on Robotics and Biomimetics (ROBIO), pp. 361-366, Kuala Lumpur, Malaysia, December 2018. 
[41] R. Coulson, M. Kirkpatrick, M. Robinson, M. Donahue, and D. R. Berg, User Testing of a Continuum Manipulator for Assistive Technology, RESNA, Arlington, VA, USA, 2018.

[42] C. Cheng, J. Cheng, and W. Huang, "Design and development of a novel SMA actuated multi-DOF soft robot," IEEE Access, vol. 7, pp. 75073-75080, 2019.

[43] X. Chen, Y. Guo, D. Duanmu, J. Zhou, W. Zhang, and Z. Wang, "Design and modeling of an extensible soft robotic arm," IEEE Robotics and Automation Letters, vol. 4, no. 4, pp. 4208-4215, 2019.

[44] G. Olson, B. Woronowicz, and Y. Mengüç, "Characterization of a class of soft bending arms," in Proceedings of the 2019 2nd IEEE International Conference on Soft Robotics (RoboSoft), pp. 462-469, Seoul, South Korea, April 2019.

[45] N. P. Castledine, J. H. Boyle, and J. Kim, "Design of a modular continuum robot segment for use in a general purpose manipulator," in Proceedings of the 2019 International Conference on Robotics and Automation (ICRA), pp. 4430-4435, Montreal, Canada, May 2019.

[46] J. D. Greer, T. K. Morimoto, A. M. Okamura, and E. W. Hawkes, "Series pneumatic artificial muscles (sPAMs) and application to a soft continuum robot," in Proceedings of the 2017 IEEE International Conference on Robotics and Automation (ICRA), pp. 5503-5510, Singapore, May 2017.

[47] M. Bamdad and A. Mardani, "Design and analysis of a novel tendon-less backbone robot," International Journal of Robotics, vol. 4, no. 3, pp. 55-65, 2015.

[48] S. Wang and W. Zhang, "The Fluid-Skeleton Elastic Manipulator (FSEM): a novel solution for highly maneuverable robotic arms," in Proceedings of the 2016 IEEE International Conference on Robotics and Biomimetics (ROBIO), pp. 521526, Kuala Lumpur, Malaysia, December 2016.

[49] U. Chouinard, S. Achiche, T. Bieze, L. Baron, and C. Duriez, "Analyzing design modification effects on the compliance of deformable hybrid serial-parallel manipulators," in Proceedings of the Mechanisms, Machines and Mechatronics Symposium-2017, pp. 1-12, Ottawa, Canada, May 2017.

[50] A. L. Orekhov, V. A. Aloi, and D. C. Rucker, "Modeling parallel continuum robots with general intermediate constraints," in Proceedings of the 2017 IEEE International Conference on Robotics and Automation (ICRA), pp. 61426149, Singapore, May 2017.

[51] A. Shikari and H. Asada, "Triple scissor extender robot arm: a solution to the last one foot problem of manipulation," IEEE Robotics and Automation Letters, vol. 3, no. 4, pp. 3975-3982, 2018.

[52] A. Ataka, A. Shiva, H. K. Lam, and K. Althoefer, "Magneticfield-inspired navigation for soft continuum manipulator," in Proceedings of the 2018 IEEE/RSJ International Conference on Intelligent Robots and Systems (IROS), pp. 168-173, Singapore, October 2018.

[53] T. Liu, Z. Mu, H. Wang, W. Xu, and Y. Li, "A cable-driven redundant spatial manipulator with improved stiffness and load capacity," in Proceedings of the 2018 IEEE/RSJ International Conference on Intelligent Robots and Systems (IROS), pp. 6628-6633, Madrid, Spain, October 2018.

[54] D. Alatorre, B. Nasser, A. Rabani et al., Robotic Bore Blending: The Future of In-Situ Gas Turbine Repair, IROS, Madrid, Spain, 2018.

[55] E. Y. Yarbasi and E. Samur, "Design and evaluation of a continuum robot with extendable balloons," Mechanical Sciences, vol. 9, no. 1, pp. 51-60, 2018.

[56] I. A. Gravagne and I. D. Walker, "On the kinematics of remotely-actuated continuum robots," in Proceedings of the
2000 ICRA. Millennium Conference. IEEE International Conference on Robotics and Automation. Symposia Proceedings (Cat. No. 00CH37065), vol. 3, pp. 2544-2550, San Francisco, CA, USA, April 2000.

[57] P. Qi, C. Qiu, H. Liu, J. S. Dai, L. Seneviratne, and K. Althoefer, "A novel continuum-style robot with multilayer compliant modules," in Proceedings of the 2014 IEEE/ RSJ International Conference on Intelligent Robots and Systems, pp. 3175-3180, Chicago, IL, USA, September 2014.

[58] T. D. Nguyen and J. Burgner-Kahrs, "A tendon-driven continuum robot with extensible sections," in Proceedings of the 2015 IEEE/RSJ International Conference on Intelligent Robots and Systems (IROS), pp. 2130-2135, Hamburg, Germany, September-October 2015.

[59] B. Ouyang, Y. Liu, H.-Y. Tam, and D. Sun, "Design of an interactive control system for a multisection continuum robot," IEEE/ASME Transactions on Mechatronics, vol. 23, no. 5, pp. 2379-2389, 2018.

[60] M. T. Chikhaoui, S. Lilge, S. Kleinschmidt, and J. BurgnerKahrs, "Comparison of modeling approaches for a tendon actuated continuum robot with three extensible segments," IEEE Robotics and Automation Letters, vol. 4, no. 2, pp. 989-996, 2019.

[61] H. Guo, F. Ju, Y. Cao et al., "Continuum robot shape estimation using permanent magnets and magnetic sensors," Sensors and Actuators A: Physical, vol. 285, pp. 519-530, 2019.

[62] H. S. Yoon and B. J. Yi, "A 4-DOF flexible continuum robot using a spring backbone," in Proceedings of the 2009 International Conference on Mechatronics and Automation, pp. 1249-1254, Jilin, China, August 2009.

[63] Z. Li and R. Du, "Design and implementation of a biomimetic wire-driven underactuated serpentine manipulator," Transaction on Control and Mechanical Systems, vol. 1, pp. 250-258, 2012.

[64] Y. Yang and W. Zhang, "An elephant-trunk manipulator with twisting flexional rods," in Proceedings of the 2015 IEEE International Conference on Robotics and Biomimetics (ROBIO), pp. 13-18, Zhuhai, China, December 2015.

[65] L. Tang, J. Wang, Y. Zheng, G. Gu, L. Zhu, and X. Zhu, "Design of a cable-driven hyper-redundant robot with experimental validation," International Journal of Advanced Robotic Systems, vol. 14, no. 5, 2017.

[66] W. Xu, T. Liu, and Y. Li, "Kinematics, dynamics, and control of a cable-driven hyper-redundant manipulator," IEEE/ ASME Transactions on Mechatronics, vol. 23, no. 4, pp. 1693-1704, 2018.

[67] B. Zhao, W. Zhang, Z. Zhang, X. Zhu, and K. Xu, "Continuum manipulator with redundant backbones and constrained bending curvature for continuously variable stiffness," in Proceedings of the 2018 IEEE/RSJ International Conference on Intelligent Robots and Systems (IROS), pp. 7492-7499, Madrid, Spain, October 2018.

[68] S. Neppalli and B. A. Jones, "Design, construction, and analysis of a continuum robot," in Proceedings of the 2007 IEEE/RSJ International Conference on Intelligent Robots and Systems, pp. 1503-1507, San Diego, CA, USA, OctoberNovember 2007.

[69] D. L. Bakker, D. Matsuura, Y. Takeda, and J. L. Herder, "Design of an environmentally interactive continuum manipulator," in Proceedings of the 14th World Congress in Mechanism and Machine Science, IFToMM, Taipei, Tajwan, September 2015. 
[70] H. Mao, J. Santoso, C. Onal, and J. Xiao, "Sim-to-real transferable object classification through touch-based continuum manipulation," in Proceedings of the International Symposium on Experimental Robotics (ISER), Springer, Buenos Aires, Argentina, November 2018.

[71] A. Al-Ibadi, S. Nefti-Meziani, and S. Davis, "Design, kinematics and controlling a novel soft robot arm with parallel motion," Robotics, vol. 7, no. 2, p. 19, 2018.

[72] M. Giorelli, F. Renda, M. Calisti, A. Arienti, G. Ferri, and C. Laschi, "Neural network and jacobian method for solving the inverse statics of a cable-driven soft arm with nonconstant curvature," IEEE Transactions on Robotics, vol. 31, no. 4, pp. 823-834, 2015.

[73] F. Renda, M. Cianchetti, M. Giorelli, A. Arienti, and C. Laschi, "A 3D steady-state model of a tendon-driven continuum soft manipulator inspired by the octopus arm," Bioinspiration \& Biomimetics, vol. 7, no. 2, Article ID 025006, 2012.

[74] A. Arienti, M. Calisti, F. Giorgio-Serchi, and C. Laschi, "PoseiDRONE: design of a soft-bodied ROV with crawling, swimming and manipulation ability," in Proceedings of the 2013 OCEANS, pp. 1-7, San Diego, CA, USA, September 2013.

[75] C. Laschi, M. Cianchetti, B. Mazzolai, L. Margheri, M. Follador, and P. Dario, "Soft robot arm inspired by the Octopus," Advanced Robotics, vol. 26, no. 7, pp. 709-727, 2012.

[76] M. Cianchetti, F. Renda, A. Licofonte, and C. Laschi, "Sensorization of continuum soft robots for reconstructing their spatial configuration," in Proceedings of the 2012 4th IEEE RAS \& EMBS International Conference on Biomedical Robotics and Biomechatronics (BioRob), pp. 634-639, Rome, Italy, June 2012.

[77] W. McMahan and I. D. Walker, "Octopus-inspired graspsynergies for continuum manipulators," in Proceedings of the 2008 IEEE International Conference on Robotics and Biomimetics, pp. 945-950, Bangkok, Thailand, February 2009.

[78] E. Guglielmino, N. Tsagarakis, and D. G. Caldwell, "An octopus anatomy-inspired robotic arm," in Proceedings of the 2010 IEEE/RSJ International Conference on Intelligent Robots and Systems, pp. 3091-3096, October 2010.

[79] M. Calisti, M. Giorelli, G. Levy et al., "An octopus-bioinspired solution to movement and manipulation for soft robots," Bioinspiration \& Biomimetics, vol. 6, no. 3, Article ID 036002, 2011.

[80] I. S. Godage, D. T. Branson, E. Guglielmino, G. A. MedranoCerda, and D. G. Caldwell, "Shape function-based kinematics and dynamics for variable length continuum robotic arms," in Proceedings of the 2011 IEEE International Conference on Robotics and Automation, pp. 452-457, Shanghai, China, May 2011.

[81] E. Guglielmino, I. Godage, L. Zullo, and D. G. Caldwell, “A pragmatic bio-inspired approach to the design of octopusinspired arms," in Proceedings of the 2013 IEEE/RSJ International Conference on Intelligent Robots and Systems, pp. 4577-4582, Tokyo, Japan, November 2013.

[82] T. Zheng, Y. Yang, D. T. Branson et al., "Control design of shape memory alloy based multi-arm continuum robot inspired by octopus," in Proceedings of the 2014 9th IEEE Conference on Industrial Electronics and Applications, pp. 1108-1113, Hangzhou, China, June 2014.

[83] J. Fras, M. Macias, Y. Noh, and K. Althoefer, "Fluidical bending actuator designed for soft octopus robot tentacle," in Proceedings of the 2018 IEEE International Conference on
Soft Robotics (RoboSoft), pp. 253-257, Livorno, Italy, April 2018.

[84] H. Wang, S. Fan, F. Ni, and H. Liu, "Biologically inspired guidelines for the design of the hyper-dexterous manipulator," in Proceedings of the 2016 IEEE International Conference on Mechatronics and Automation, pp. 641-646, Harbin, China, August 2016.

[85] Z. Yang, X. Zhu, and K. Xu, "Continuum delta robot: a novel translational parallel robot with continuum joints," in Proceedings of the 2018 IEEE/ASME International Conference on Advanced Intelligent Mechatronics (AIM), pp. 748-755, Auckland, New Zealand, July 2018.

[86] M. Blessing and I. D. Walker, "Novel continuum robots with variable-length sections," IFAC Proceedings Volumes, vol. 37, no. 14, pp. 55-60, 2004.

[87] G. Boccolato, F. Manta, S. Dumitru, and D. Cojocaru, "3D control for a tentacle robot," in Proceedings of the 3rd International Conference on Applied Mathematics, Simulation, Modelling (ASM'09), pp. 29-31, Stevens Point, WI, USA, December 2009.

[88] D. Devereux, P. Nutter, and R. Richardson, "Determining an Object's Shape with a Blind Tactile Manipulator," in Proceedings of the 2009 IEEE/RSJ International Conference on Intelligent Robots and Systems, pp. 4745-4750, St. Louis, MO, USA, October 2009.

[89] B. He, Z. Wang, Q. Li, H. Xie, and R. Shen, "An analytic method for the kinematics and dynamics of a multiplebackbone continuum robot," International Journal of Advanced Robotic Systems, vol. 10, no. 1, p. 84, 2013.

[90] S. Sanan, J. Moidel, and C. G. Atkeson, "A continuum approach to safe robots for physical human interaction," in Proceedings of the International Symposium on Quality of Life Technology (isQoLT), Toronto, Canada, June 2011.

[91] M. Eder, M. Karl, A. Knoll, and S. Riesner, "Continuum worm-like robotic mechanism with decentral control architecture," in Proceedings of the 2014 IEEE International Conference on Automation Science and Engineering (CASE), pp. 866-871, Taipei, Taiwan, August 2014.

[92] F. Maghooa, A. Stilli, Y. Noh, K. Althoefer, and H. A. Wurdemann, "Tendon and pressure actuation for a bio-inspired manipulator based on an antagonistic principle," in Proceedings of the 2015 IEEE International Conference on Robotics and Automation (ICRA), pp. 2556-2561, Seattle, WA, USA, May 2015.

[93] K. Zhang, C. Qiu, and J. S. Dai, "An extensible continuum robot with integrated origami parallel modules," Journal of Mechanisms and Robotics, vol. 8, no. 3, Article ID 031010, 2016.

[94] M. T. Chikhaoui, A. Cot, K. Rabenorosoa, P. Rougeot, and N. Andreff, "Design and closed-loop control of a tri-layer polypyrrole based telescopic soft robot," in Proceedings of the 2016 IEEE/RSJ International Conference on Intelligent Robots and Systems (IROS), pp. 1145-1150, Daejeon, South Korea, October 2016.

[95] Z. Gong, Z. Xie, X. Yang, T. Wang, and L. Wen, "Design, fabrication and kinematic modeling of a 3D-motion soft robotic arm," in Proceedings of the 2016 IEEE International Conference on Robotics and Biomimetics (ROBIO), pp. 509514, Qingdao, China, December 2016.

[96] J. Lee, E. Go, W. Choi, W. Kim, and K. Cho, "Development of Soft Continuum Manipulator with Pneumatic and Tendon Driven Actuations," in Proceedings of the 2016 13th International Conference on Ubiquitous Robots and 
Ambient Intelligence (URAI) (Xi'an), pp. 377-379, Xian, China, August 2016.

[97] M. M. Dalvand, S. Nahavandi, and R. D. Howe, "High speed vision-based 3D reconstruction of continuum robots," in Proceedings of the 2016 IEEE International Conference on Systems, Man, and Cybernetics (SMC), pp. 000618-000623, Budapest, Hungary,, October 2016.

[98] Y. Tian, S. Yang, H. Geng, W. Wang5, and L. Li, "Kinematic modeling of the constant curvature continuum line drive robot," in Proceedings of the 2016 IEEE International Conference on Robotics and Biomimetics (ROBIO), pp. 289-294, Qingdao, China, December 2016.

[99] H. Wang, C. Wang, W. Chen, X. Liang, and Y. Liu, "Threedimensional dynamics for cable-driven soft manipulator," IEEE/ASME Transactions on Mechatronics, vol. 22, no. 1, pp. 18-28, 2016.

[100] A. Ataka, P. Qi, A. Shiva et al., "Towards safer obstacle avoidance for continuum-style Manipulator in dynamic environments," in Proceedings of the 2016 6th IEEE International Conference on Biomedical Robotics and Biomechatronics (BioRob), pp. 600-605, UTown, Singapore, June 2016.

[101] Y. Wang and K. Lee, "3D-printed semi-soft mechanisms inspired by origami twisted towers," in Proceedings of the 2017, NASA/ESA Conference on Adaptive Hardware and Systems (AHS), pp. 161-166, Pasadena, CA, USA, July 2017.

[102] C. Meng, W. Xu, H. Li, H. Zhang, and D. Xu, “A new design of cellular soft continuum manipulator based on beehiveinspired modular structure," International Journal of Advanced Robotic Systems, vol. 14, no. 3, p. 1729881417707380 , 2017.

[103] Y. Zhang, M. Su, M. Li, R. Xie, H. Zhu, and Y. Guan, “A spatial soft module actuated by SMA coil," in Proceedings of the 2017 IEEE International Conference on Mechatronics and Automation (ICMA), pp. 677-682, Kagawa, Japan, August 2017.

[104] K. Hsiao and H. Mochiyama, "A wire-driven continuum manipulator model without assuming shape curvature constancy," in Proceedings of the 2017 IEEE/RSJ International Conference on Intelligent Robots and Systems (IROS), pp. 436-443, Vancouver, Canada, September 2017.

[105] S. H. Sadati, S. E. Naghibi, I. D. Walker, K. Althoefer, and T. Nanayakkara, "Control space reduction and real-time accurate modeling of continuum manipulators using ritz and ritz-galerkin methods," IEEE Robotics and Automation Letters, vol. 3, no. 1, pp. 328-335, 2017.

[106] J. Santoso, E. H. Skorina, M. Luo, R. Yan, and C. D. Onal, "Design and analysis of an origami continuum manipulation module with torsional strength," in Proceedings of the 2017 IEEE/RSJ International Conference on Intelligent Robots and Systems (IROS), pp. 2098-2104, Vancouver, Canada, September 2017.

[107] T. Chanthasopeephan, P. Srikirin, M. Srisap, and A. Rattapat, "Flexure design of a compliant modular hyperredundant manipulator," in Proceedings of the 2017 26th IEEE International Symposium on Robot and Human Interactive Communication (RO-MAN), pp. 1394-1399, Lisbon, Portugal, August 2017.

[108] G. Wu, G. Shi, and Y. Shi, "). Modeling and analysis of a parallel continuum robot using artificial neural networks," in Proceedings of the 2017 IEEE International Conference on Mechatronics (ICM), pp. 153-158, Gippsland, Australia, February 2017.
[109] Z. Jiang, Y. Luo, and Y. Jin, "New cable-driven continuum robot with only one actuator," in Proceedings of the 2017 IEEE International Conference on Cybernetics and Intelligent Systems (CIS) and IEEE Conference on Robotics, Automation and Mechatronics (RAM), pp. 693-698, Ningbo, China, November 2017.

[110] P. Yao, K. Li, Z. Xu, Z. Wang, and G. Bao, "Bending model of a novel long-arm biomimetic robot," in Proceedings of the 2017 IEEE International Conference on Real-Time Computing and Robotics (RCAR), pp. 115-120, Okinawa, Japan, July 2017.

[111] T. Liu, Y. Wang, and K. Lee, "Three-dimensional printable origami twisted tower: design, fabrication, and robot embodiment," IEEE Robotics and Automation Letters, vol. 3, no. 1, pp. 116-123, 2017.

[112] J. D. Ho, K. H. Lee, W. L. Tang, K. Althoefer, J. Lam, and K. W. Kwok, "Control of a soft redundant manipulator under variable loading through localized online learning," Advanced Robotics, vol. 32, no. 21, pp. 1168-1183.

[113] S. Mosqueda, Y. Moncada, C. Murrugarra, and H. LeónRodriguez, "Constant curvature kinematic model analysis and experimental validation for tendon driven continuum manipulators," in Proceedings of the ICINCO, no. 2, pp. 221-228, Portu, Portugal, July 2018.

[114] L. Manfredi, L. Yue, J. Zhang, and A. Cuschieri, "A 4 DOFs variable stiffness soft module," in Proceedings of the 2018 IEEE International Conference on Soft Robotics (RoboSoft), pp. 94-99, Livorno, Italy, April 2018.

[115] F. Xu, H. Wang, K. W. S. Au, W. Chen, and Y. Miao, "Underwater dynamic modeling for a cable-driven soft robot arm," IEEE/ASME Transactions on Mechatronics, vol. 23, no. 6, pp. 2726-2738, 2018.

[116] K. T. Song and H. C. Tsai, "Visual servoing and compliant motion control of a continuum robot," in Proceedings of the 2018 18th International Conference on Control, Automation and Systems (ICCAS), pp. 734-739, PyeongChang, South Korea, October 2018.

[117] N. Lin, P. Wu, M. Wang, F. Yang, J. Wei, and X. Chen, "Design and control of a soft combined actuator," in Proceedings of the 2018 WRC Symposium on Advanced Robotics and Automation (WRC SARA), pp. 255-260, Beijing, China, August 2018.

[118] A. Ishii, Y. Ambe, Y. Yamauchi et al., "Design and development of biaxial active nozzle with flexible flow channel for air floating active scope camera," in Proceedings of the 2018 IEEE/RSJ International Conference on Intelligent Robots and Systems (IROS), pp. 442-449, Madrid, Spain, October 2018.

[119] C. Wang, C. Yang, and R. Kang, "Kinematic flexibility analysis of a wire-driven continuum robot," in Proceedings of the 2018 IEEE International Conference on Robotics and Biomimetics (ROBIO), pp. 337-342, Kuala Lumpur, Malaysia, December 2018.

[120] N. K. Uppalapati and G. Krishnan, "Design of soft continuum manipulators using parallel asymmetric combination of fiber reinforced elastomers,", 2018.

[121] A. Mishra, A. Mondini, E. Del Dottore, A. Sadeghi, F. Tramacere, and B. Mazzolai, "Modular continuum manipulator: analysis and characterization of its basic module," Biomimetics, vol. 3, no. 1, p. 3, 2018.

[122] X. Peng, N. Zhang, L. Ge, and G. Gu, "Dimension optimization of pneumatically actuated soft continuum manipulators," in Proceedings of the 2019 2nd IEEE International Conference on Soft Robotics (RoboSoft), pp. 13-18, Seoul, South Korea, April 2019. 
[123] G. Wu and G. Shi, "Experimental statics calibration of a multi-constraint parallel continuum robot," Mechanism and Machine Theory, vol. 136, pp. 72-85, 2019.

[124] A. A. Nazari, D. Castro, and I. S. Godage, "Forward and inverse kinematics of a single section inextensible continuum arm," in Proceedings of the DePaul School of Computing \& Digital Media (SCD) Research Symposium, Chicago, IL, USA, 2019, http://arxiv.org/abs/1907.06518.

[125] N. Lin, P. Wu, M. Wang et al., "IMU-based active safe control of a variable stiffness soft actuator," IEEE Robotics and Automation Letters, vol. 4, no. 2, pp. 1247-1254, 2019.

[126] F. Xu, H. Wang, J. Wang, K. W. S. Au, and W. Chen, "Underwater dynamic visual servoing for a soft robot arm with online distortion correction," IEEE/ASME Transactions on Mechatronics, vol. 24, no. 3, pp. 979-989, 2019.

[127] J. C. Case, M. C. Yuen, J. Jacobs, and R. Kramer-Bottiglio, "Robotic skins that learn to control passive structures," IEEE Robotics and Automation Letters, vol. 4, no. 3, pp. 24852492, 2019.

[128] H. B. Gilbert and I. S. Godage, "Validation of an extensible rod model for soft continuum manipulators," in Proceedings of the 2019 2nd IEEE International Conference on Soft Robotics (RoboSoft), pp. 711-716, Seoul, South Korea, April 2019.

[129] G. Fang, X. Wang, K. Wang et al., "Vision-based online learning kinematic control for soft robots using local Gaussian process regression," IEEE Robotics and Automation Letters, vol. 4, no. 2, pp. 1194-1201, 2019.

[130] J. Garbulinski and N. M. Wereley, "Workspace analysis of multi-section continuum pneumatic arm," in Proceedings of the 2019 SMART, p. 167, Paris, France, 2019.

[131] X. XFang, G. Bao, and Q. Yang, "Design and modeling of a novel variable stiffness mechanism," in Proceedings of the 2018 IEEE International Conference on Robotics and Biomimetics (ROBIO), pp. 2491-2495, Kuala Lumpur, Malaysia, December 2018.

[132] P. Sabetian, A. Feizollahi, F. Cheraghpour, and S. A. A. Moosavian, "A compound robotic hand with two under-actuated fingers and a continuous finger," in Proceedings of the IEEE International Symposium on Safety, Security, and Rescue Robotics, pp. 238-244, Kyoto, Japan, June 2011.

[133] G. Bao, S. Cai, Z. Wang et al., "Flexible pneumatic robotic actuator FPA and its applications," in Proceedings of the IEEE International Conference on Robotics and Biomimetics (ROBIO), pp. 867-872, Shenzhen, China, December 2013.

[134] M. Dehghani and S. A. A. Moosavian, "Dynamics modeling of a continuum robotic arm with a contact point in planar grasp," Journal of Robotics, vol. 2014, Article ID 308283, 13 pages, 2014.

[135] S. Tiefeng, D. Mingyu, B. Guanjun, Z. Libin, and Y. Qinghua, "Fruit harvesting continuum manipulator inspired by elephant trunk," International Journal of Agricultural and Biological Engineering, vol. 8, no. 1, pp. 57-63, 2015.

[136] R. Mutlu, S. K. Yildiz, G. ., M. Alici, and G. M. Spinks, "Mechanical stiffness augmentation of a 3D printed soft prosthetic finger," in Proceedings of the IEEE International Conference on Advanced Intelligent Mechatronics (AIM), pp. 7-12, Banff, Alberta, Canada, July 2016.

[137] A. Al-Ibadi, S. Nefti-Meziani, and S. Davis, "Cooperative project by self-bending continuum arms," in Proceedings of the 23rd International Conference on Automation and Computing (ICAC), pp. 1-6, Huddersfield, UK, September 2017.
[138] L. A. T. Al Abeach, S. Nefti-Meziani, and S. Davis, "Design of a variable stiffness soft dexterous gripper," Soft Robotics, vol. 4, no. 3, pp. 274-284, 2017.

[139] R. Wakatabe, Y. Kuniyoshi, and G. Cheng, "O (logn) algorithm for forward kinematics under asynchronous sensory input," in Proceedings of the IEEE International Conference on Robotics and Automation (ICRA), pp. 2502-2507, Singapore, May 2017.

[140] Y. Hao, T. Wang, Z. Xie et al., "A eutectic-alloy-infused soft actuator with sensing, tunable degrees of freedom, and stiffness properties," Journal of Micromechanics and Microengineering, vol. 28, no. 2, Article ID 024004, 2018.

[141] M. A. Robertson and J. Paik, "Low-inertia vacuum-powered soft pneumatic actuator coil characterization and design methodology," in Proceedings of the IEEE International Conference on Soft Robotics (RoboSoft), pp. 431-436, Livorno, Italy, April 2018.

[142] G. Carabin, V. Renato, and M. Dominik, "Performance characterization and improvement of an underactuated robot gripper," in Proceedings of the ISR 2018; 50th International Symposium on Robotics, pp. 1-7, Munich, Germany, June 2018.

[143] D. Drotman, M. Ishida, S. Jadhav, and M. T. Tolley, “Application-driven design of soft, 3-D printed, pneumatic actuators with bellows," IEEE/ASME Transactions on Mechatronics, vol. 24, no. 1, pp. 78-87, 2018.

[144] C. Schlagenhauf, D. Bauer, K. H. Chang et al., "Control of tendon-driven soft foam robot hands," in Proceedings of the IEEE-RAS 18th International Conference on Humanoid Robots (Humanoids), pp. 1-7, Beijing, China, November 2018.

[145] G. Yang, C. Zhang, Y. Wang, W. Shen, Z. Fang, and G. Ye, "Self-Calibration of cable driven continuum robot," in Proceedings of the IEEE International Conference on Robotics and Biomimetics (ROBIO), pp. 2498-2503, Dali, China, December 2018.

[146] Y. A. Seong, R. Niiyama, Y. Kawahara, and Y. Kuniyoshi, "Low-pressure soft inflatable joint driven by inner tendon," in Proceedings of the IEEE International Conference on Soft Robotics (RoboSoft), pp. 37-42, Seoul, South Korea, April 2019.

[147] S. Sanan, M. H. Ornstein, and C. G. Atkeson, "Physical human interaction for an inflatable manipulator," in Proceedings of the 2011 Annual International Conference of the IEEE Engineering in Medicine and Biology Society, pp. 7401-7404, Boston, MA, USA, August 2011.

[148] K. Xu, D. Qiu, and N. Simaan, "A pilot investigation of continuum robots as a design alternative for upper extremity exoskeletons," in Proceedings of the IEEE International Conference on Robotics and Biomimetics, pp. 656-662, Phuket, Thailand, December 2011.

[149] A. D. Marchese, R. K. Katzschmann, and D. Rus, "Whole arm planning for a soft and highly compliant $2 \mathrm{~d}$ robotic manipulator," in Proceedings of the IEEE/RSJ International Conference on Intelligent Robots and Systems, pp. 554-560, Chicago, IL, USA, September 2014.

[150] G. J. Bao, X. L. Ma, X. Y. Luo, T. F. Shao, L. B. Zhang, and Q. H. Yang, "Full compliant continuum robotic finger and its kinematic model," Iranian Journal of Science and Technology, vol. 38, no. M2, p. 389, 2014.

[151] A. Gregg-Smith and W. W. Mayol-Cuevas, "The design and evaluation of a cooperative handheld robot," in Proceedings of the IEEE International Conference on Robotics and 
Automation (ICRA), pp. 1968-1975, Seattle, WA, USA, May 2015.

[152] T. Nierhoff, K. Leibrandt, T. Lorenz, and S. Hirche, "Robotic billiards: understanding humans in order to counter them," IEEE Transactions on Cybernetics, vol. 46, no. 8, pp. 18891899, 2015.

[153] X. Liang, H. Cheong, Y. Sun, J. Guo, C. K. Chui, and C.-H. Yeow, "Design, characterization, and implementation of a two-DOF fabric-based soft robotic arm," IEEE Robotics and Automation Letters, vol. 3, no. 3, pp. 2702-2709, 2018.

[154] T. Kim, S. J. Yoon, and Y.-L. Park, "Soft inflatable sensing modules for safe and interactive robots," IEEE Robotics and Automation Letters, vol. 3, no. 4, pp. 3216-3223, 2018.

[155] P. Hyatt, D. Kraus, V. Sherrod, L. Rupert, N. Day, and M. D. Killpack, "Configuration estimation for accurate position control of large-scale soft robots," IEEE/ASME Transactions on Mechatronics, vol. 24, no. 1, pp. 88-99, 2018.

[156] S. Xu, G. Li, D. Song, L. Sun, and J. Liu, "Real-time shape recognition of a deformable link by using a self-organizing map," in Proceedings of the IEEE 14th International Conference on Automation Science and Engineering (CASE), pp. 586-591, Munich, Germany, August 2018.

[157] K. Xu, Z. Liu, B. Zhao, H. Liu, and X. Zhu, "Composed continuum mechanism for compliant mechanical postural synergy: an anthropomorphic hand design example," Mechanism and Machine Theory, vol. 132, pp. 108-122, 2019.

[158] A. L. Orekhov, G. L. Johnston, C. Abah, H. Choset, and N. Simaan, "Towards collaborative robots with sensory awareness: preliminary results using multi-modal sensing," in Proceedings of the ICRA-2019, Montreal, Canada, May 2019.

[159] K. Zhang, Y. Zhu, C. Lou, P. Zheng, and M. Kovač, “A design and fabrication approach for pneumatic soft robotic arms using 3D printed origami skeletons," in Proceedings of the IEEE International Conference on Soft Robotics (RoboSoft), pp. 821-827, Seoul, South Korea, April 2019.

[160] T. Suzuki, Y. Ebihara, Y. Ando, and M. Mizukawa, "Casting and winding manipulation with hyper-flexible manipulators," in Proceedings of the IEEE/RSJ International Conference on Intelligent Robots and Systems, pp. 1674-1679, Beijing, China, October 2006.

[161] J. S. Mehling, M. A. Diftler, M. Chu, and M. Valvo, "A minimally invasive tendril robot for in-space inspection," in Proceedings of the IEEE/RAS-EMBS International Conference on Biomedical Robotics and Biomechatronics. BioRob 2006, pp. 690-695, Pisa, Italy, February 2006.

[162] M. B. Wooten and I. D. Walker, "A novel vine-like robot for in-orbit inspection," in Proceedings of the 45th International Conference on Environmental Systems, pp. 1-11, Bellevue, WA, USA, July 2015.

[163] M. M. Tonapi, I. S. Godage, and I. D. Walker, "Design, modeling and performance evaluation of a long and slim continuum robotic cable," in Proceedings of the IEEE/RSJ International Conference on Intelligent Robots and Systems, pp. 2852-2859, Chicago, IL, USA, September 2014.

[164] M. Wooten, C. Frazelle, I. D. Walker, A. Kapadia, and J. H. Lee, "Exploration and inspection with vine-inspired continuum robots," in Proceedings of the IEEE International Conference on Robotics and Automation (ICRA), pp. 1-5, Brisbane, Australia, May 2018.

[165] M. Wooten and I. Walker, "Vine-inspired continuum tendril robots and circumnutations," Robotics, vol. 7, no. 3, p. 58, 2018 .
[166] N. Guochen, W. Li, G. Qingji, and H. Dandan, "Pathtracking algorithm for aircraft fuel tank inspection robots," International Journal of Advanced Robotic Systems, vol. 11, no. 5 , p. 82, 2014.

[167] G. P. Scott, C. G. Henshaw, I. D. Walker, and B. Willimon, "Autonomous robotic refueling of an unmanned surface vehicle in varying sea states," in Proceedings of the IEEE/RSJ International Conference on Intelligent Robots and Systems (IROS), pp. 1664-1671, Hamburg, Germany, SeptemberOctober 2015.

[168] H. Yin, X. Zhang, J. Li, and J. Cao, "Grasping model and experiment of a soft robot gripper with variable stiffness," in Proceedings of the IEEE International Conference on Cybernetics and Intelligent Systems (CIS) and IEEE Conference on Robotics, Automation and Mechatronics (RAM), pp. 134-139, Qingdao, China, November 2017.

[169] D. Nahar, P. M. Yanik, and I. D. Walker, "Robot tendrils: long, thin continuum robots for inspection in space operations," in Proceedings of the IEEE Aerospace Conference, pp. 1-8, Big Sky, MT, USA, March 2017.

[170] I. D. Walker, "Use of continuum robots for remote inspection operations," in Proceedings of the Computing Conference, pp. 1382-1385, London, UK, July 2017.

[171] H. Ando, Y. Ambe, A. Ishii et al., "Aerial hose type robot by water jet for fire fighting," IEEE Robotics and Automation Letters, vol. 3, no. 2, pp. 1128-1135, 2018.

[172] M. Wang, D. Palmer, X. Dong, D. Alatorre, D. Axinte, and A. Norton, "Design and development of a slender dualstructure continuum robot for in-situ aeroengine repair," in Proceedings of the IEEE/RSJ International Conference on Intelligent Robots and Systems (IROS), pp. 5648-5653, Madrid, Spain, October 2018.

[173] G. Niu, J. Wang, and K. Xu, "Model analysis for a continuum aircraft fuel tank inspection robot based on the Rzeppa universal joint," Advances in Mechanical Engineering, vol. 10, no. $5,2018$.

[174] M. M. Coad, L. H. Blumenschein, S. Cutler et al., "Vine robots: design, teleoperation, and deployment for navigation and exploration," IEEE Robotics and Automation Magazine, http://arxiv.org/abs/1903.00069, 2019.

[175] H. El-Hussieny, U. Mehmood, Z. Mehdi, S. G. Jeong, M. Usman, E. W. ., ... Hawkes et al., "Development and evaluation of an intuitive flexible interface for teleoperating soft growing robots," in Proceedings of the IEEE/RSJ International Conference on Intelligent Robots and Systems (IROS), pp. 4995-5002, Madrid, Spain, October 2018.

[176] A. Kanada and T. Mashimo, "Mobile continuum robot with unlimited extensible sections," in Proceedings of the IEEE/ RSJ International Conference on Intelligent Robots and Systems (IROS), pp. 7117-7122, Madrid, Spain, October 2018.

[177] L. H. Blumenschein, N. S. Usevitch, B. H. Do, E. W. Hawkes, and A. M. Okamura, "Helical actuation on a soft inflated robot body," in Proceedings of the IEEE International Conference on Soft Robotics (RoboSoft), pp. 245-252, Livorno, Italy, April 2018.

[178] E. Amanov, T.-D. Nguyen, and J. Burgner-Kahrs, “Tendondriven continuum robots with extensible sections-a modelbased evaluation of path-following motions," The International Journal of Robotics Research, 2019.

[179] L. H. Blumenschein, L. T. Gan, J. A. Fan, A. M. Okamura, and E. W. Hawkes, "A tip-extending soft robot enables reconfigurable and deployable antennas," IEEE Robotics and Automation Letters, vol. 3, no. 2, pp. 949-956, 2018. 
[180] E. Amanov, J. Granna, and J. Burgner-Kahrs, "Toward improving path following motion: hybrid continuum robot design," in Proceedings of the IEEE International Conference on Robotics and Automation (ICRA), pp. 4666-4672, Singapore, May-June 2017.

[181] F. Putzu, T. Abrar, and K. Althoefer, "Plant-inspired soft pneumatic Eversion robot," in Proceedings of the IEEE International Conference on Biomedical Robotics and Biomechatronics (Biorob), pp. 1327-1332, Enschede, The Netherlands, August 2018.

[182] W. S. Rone and P. Ben-Tsvi, "Continuum robotic tail loading analysis for mobile robot stabilization and maneuvering," in Proceedings of the ASME International Design Engineering Technical Conferences \& Computers and Information in Engineering Conference, pp. 1-8, Buffalo, NY, USA, August 2014.

[183] Z. Zheng, K. Wang, X. Wu, Q. Zhang, and K. Li, "Dynamic analysis of elastic projecting robot inspired by chameleon tongue," in Proceedings of the IEEE International Conference on Robotics and Biomimetics (ROBIO), pp. 2088-2094, Zurich, Switzerland, December 2018.

[184] M. Benosman and G. Le Vey, "Control of flexible manipulators: a survey," Robotica, vol. 22, no. 5, pp. 533-545, 2004.

[185] T. George Thuruthel, Y. Ansari, E. Falotico, and C. Laschi, "Control strategies for soft robotic manipulators: a survey," Soft Robotics, vol. 5, no. 2, pp. 149-163, 2018.

[186] I. D. Walker, "Continuous backbone "continuum" robot manipulators," ISRN Robotics, vol. 2013, Article ID 726506, 19 pages, 2013.

[187] M. W. Hannan and I. D. Walker, "Kinematics and the implementation of an elephant's trunk manipulator and other continuum style robots," Journal of Robotic Systems, vol. 20, no. 2, pp. 45-63, 2003.

[188] W. McMahan, B. Jones, I. Walker, V. Chitrakaran, A. Seshadri, and D. Dawson, "Robotic manipulators inspired by cephalopod limbs," in Proceedings of the Canadian Engineering Education Association (CEEA), pp. 1-10, Montreal, Canada, July 2004.

[189] M. Diftler, C. A. Ihrke, L. B. Bridgwater et al., RoboGlove-A Robonaut Derived Multipurpose Assistive Device, NASA Technical Reports Server, 20140005956-JSC-CN-30211, NASA, Washington, DC, USA, 2014.

[190] M. B. Pritts and C. D. Rahn, "Design of an artificial muscle continuum robot," in Proceedings of the IEEE international conference on robotics and automation, 2004. ICRA'04, vol. 5, pp. 4742-4746, New Orleans, LA, USA, April-May 2004.

[191] D. Surdilovic, J. Radojicic, M. Schulze, and M Dembek, "Modular hybrid robots with biologically inspired actuators and joint stiffness control," in Proceedings of the IEEE RAS \& EMBS International Conference on Biomedical Robotics and Biomechatronics, pp. 289-294, Scottsdale, AZ, USA, October 2008.

[192] M. Li, R. Kang, D. T. Branson, and J. S. Dai, "Model-free control for continuum robots based on an adaptive Kalman filter," IEEE/ASME Transactions on Mechatronics, vol. 23, no. 1, pp. 286-297, 2017.

[193] S. Wakimoto, K. Suzumori, T. Kanda, and K. Kure, "Soft pressure sensor embedded in McKibben actuator," in Proceedings of the IEEE/ASME International Conference on Advanced Intelligent Mechatronics, pp. 1-6, Zurich, Switzerland, September 2007.

[194] C. Suh, J. C. Margarit, Y. S. Song, and J. Paik, "Soft pneumatic actuator skin with embedded sensors," in Proceedings of the IEEE/RSJ International Conference on
Intelligent Robots and Systems, pp. 2783-2788, Chicago, IL, USA, September 2014.

[195] R. Kang, Y. Guo, K. Cheng, and L. Chen, "Design and control of a soft actuator driven by pneumatic muscles," in Proceedings of the International Conference on Industrial Automation, Information and Communications Technology, pp. 26-30, Bali, Indonesia, August 2014.

[196] Y. Zhang, C. Xiang, H. Yang, Y. Li, and L. Hao, "Static analysis of novel continuum robot driven by PAMs," in Proceedings of the International Conference on Ubiquitous Robots and Ambient Intelligence (URAI), pp. 96-100, Xian, China, August 2016.

[197] T. Yukisawa, Y. Ishii, S. Nishikawa, R. Niiyama, and Y. Kuniyoshi, "Modeling of extensible pneumatic actuator with bellows (EPAB) for continuum arm," in Proceedings of the IEEE International Conference on Robotics and Biomimetics (ROBIO), pp. 2303-2308, Macau, China, December 2017.

[198] A. Al-Ibadi, S. Nefti-Meziani, and S. Davis, "Novel models for the extension pneumatic muscle actuator performances," in Proceedings of the International Conference on Automation and Computing (ICAC), pp. 1-6, Huddersfield, UK, September 2017.

[199] A. Al-Ibadi, S. Nefti-Meziani, and S. Davis, "Design, implementation and modelling of the single and multiple extensor pneumatic muscle actuators," Systems Science \& Control Engineering, vol. 6, no. 1, pp. 80-89, 2018.

[200] X. Chen, J. Yi, J. Li, J. Zhou, and Z. Wang, "Soft-actuatorbased robotic joint for safe and forceful interaction with controllable impact response," IEEE Robotics and Automation Letters, vol. 3, no. 4, pp. 3505-3512, 2018.

[201] J. L. Molnar, C. A. Cheng, L. O. Tiziani, B. Boots, and F. L. Hammond, "Optical sensing and control methods for soft pneumatically actuated robotic manipulators," in Proceedings of the IEEE International Conference on Robotics and Automation (ICRA), pp. 1-8, Brisbane, Australia, May 2018.

[202] H. Ru, J. Huang, W. Chen, C. Xiong, and J. Wang, "Dynamic modelling and identification of a soft bending pneumatic actuator based on visual recognition," in Proceedings of the International Conference on Advanced Robotics and Mechatronics (ICARM), pp. 600-605, Singapore, July 2018.

[203] Z. Ying, S. Yao, J. Chen, and L. Hao, "Research on kinematics modeling of soft manipulators," in Proceedings of the IEEE 8th Annual International Conference on CYBER Technology in Automation, Control, and Intelligent Systems (CYBER), pp. 1100-1105, Tianjin, China, July 2018.

[204] A. Al-Ibadi, S. Nefti-Meziani, S. Davis, and T. Theodoridis, "Design of two segments continuum robot arm based on pneumatic muscle actuator (PMA)," in Proceedings of the International Conference on Automation and Computing (ICAC), pp. 1-6, Tyne, UK, September 2018.

[205] A. Al-Ibadi, S. Nefti-Meziani, S. Davis, and T. Theodoridis, "Novel design and position control strategy of a soft robot arm," Robotics, vol. 7, no. 4, p. 72, 2018.

[206] T. A. Q. I. Abrar, F. Putzu, J. Konstantinova, and K. Althoefer, "EPAM: eversive pneumatic artificial muscle," in Proceedings of the IEEE International Conference on Soft Robotics (RoboSoft), pp. 19-24, Seoul, South Korea, April 2019.

[207] D. Bruder, A. Sedal, J. Bishop-Moser, S. Kota, and R. Vasudevan, "Model based control of fiber reinforced elastic fluidic enclosures," in Proceedings of the IEEE 
International Conference on Robotics and Automation (ICRA), pp. 5539-5544, Singapore, May-June-2017.

[208] G. Fang, X. Wang, K. Wang, K. H. Lee, D. K. C. Fu, and K. W. Kwok, "Visual servo control of a soft continuum robot using Gaussian process regression," IEEE Robotics and Automation Letters, vol. 4, no. 2, pp. 1194-1201, 2019.

[209] D. Bruder, A. Sedal, R. Vasudevan, and C. D. Remy, "Force generation by parallel combinations of fiber-reinforced fluid-driven actuators," IEEE Robotics and Automation Letters, vol. 3, no. 4, pp. 3999-4006, 2018.

[210] K. Takaki, Y. Taguchi, S. Nishikawa, R. Niiyama, and Y. Kawahara, "Acoustic length sensor for soft extensible pneumatic actuators with a frequency characteristics model," IEEE Robotics and Automation Letters, vol. 4, no. 4, pp. 4292-4297, 2019.

[211] E. Torres, K. Nakajima, and I. S. Godage, "Information processing capability of soft continuum arms," in Proceedings of the IEEE International Conference on Soft Robotics (RoboSoft), pp. 441-447, Seoul, South Korea, April 2019.

[212] J. Schmitt, F. Grabert, and A Raatz, "Design of a hyperflexible assembly robot using artificial muscles," in Proceedings of the IEEE International Conference on Robotics and Biomimetics, pp. 897-902, Tianjin, China, December 2010.

[213] R. Kang, E. Guglielmino, D. T. Branson, and D. G. Caldwell, "Kinematic model and inverse control for continuum manipulators," in Proceedings of the IEEE International Conference on Control and Automation (ICCA), pp. 1615-1620, Hangzhou, China, June 2013.

[214] R. Kang, Y. Guo, L. Chen, D. T. Branson III, and J. S. Dai, "Design of a pneumatic muscle based continuum robot with embedded tendons," IEEE/ASME Transactions on Mechatronics, vol. 22, no. 2, pp. 751-761, 2016.

[215] G. Olson and Y. Mengüç, "Helically wound soft actuators for torsion control," in Proceedings of the IEEE International Conference on Soft Robotics (RoboSoft, pp. 214-221, Livorno, Italy, April 2018.

[216] R. S. Diteesawat, T. Helps, M. Taghavi, and J. Rossiter, "High strength bubble artificial muscles for walking assistance," in Proceedings of the IEEE International Conference on Soft Robotics (RoboSoft), pp. 388-393, Livorno, Italy, April 2018.

[217] C. Morley-Drabble and S. P. Singh, "One soft robot: a complementary design \& control strategy for a pneumatically powered soft robot," in Proceedings of the IEEE/ASME International Conference on Advanced Intelligent Mechatronics, pp. 942-949, Auckland, New Zealand, July 2018.

[218] G. Gao, H. Ren, Y. Du, and H. Wang, "Research and Development of Stiffness Regulator by 3D Printing," in Proceedings of the Advanced Information Management, Communicates, Electronic and Automation Control Conference (IMCEC), pp. 785-789, Xi'an China, May 2018.

[219] N. D. Naclerio, C. M. Hubicki, Y. O. Aydin, D. I. Goldman, and E. W. Hawkes, "Soft robotic burrowing device with tipextension and granular fluidization," in Proceedings of the International Conference on Intelligent Robots and Systems (IROS), pp. 5918-5923, Madrid, Spain, October 2018.

[220] H. D. Yang and A. T. Asbeck, "A new manufacturing process for soft robots and soft/rigid hybrid robots," in Proceedings of the IEEE/RSJ International Conference on Intelligent Robots and Systems (IROS), pp. 8039-8046, Madrid, Spain, October 2018.

[221] J. Zhang, J. Sheng, C. T. ONeill et al., "Robotic artificial muscles: current progress and future perspectives," IEEE Transactions on Robotics, 2019.
[222] C. Urban, R. Gunther, T. Nagel, R. Richter, and R. Witt, "Development of a bendable permanent-magnet tubular linear motor," IEEE Transactions on Magnetics, vol. 48, no. 8 , pp. 2367-2373, 2012.

[223] S. C. Ryu and P. E. Dupont, "FBG-based shape sensing tubes for continuum robots," in Proceedings of the IEEE International Conference on Robotics and Automation (ICRA), pp. 3531-3537, Hong Kong, China, May-June 2014.

[224] T. Hassan, M. Cianchetti, B. Mazzolai, C. Laschi, and P. Dario, "Active-braid, a bioinspired continuum manipulator," IEEE Robotics and Automation Letters, vol. 2, no. 4, pp. 2104-2110, 2017

[225] A. Simeonov, T. Henderson, Z. Lan et al., "Bundled supercoiled polymer artificial muscles: design, characterization, and modeling," IEEE Robotics and Automation Letters, vol. 3, no. 3, pp. 1671-1678, 2018.

[226] X. Kong, H. Jin, Y. Chen, J. Yang, and E. Dong, “An enhanced artificial muscle module based on the decussate weaving shape memory alloy wires for soft robots," in Proceedings of the IEEE International Conference on Robotics and Biomimetics, pp. 1202-1207, Kuala Lumpur, Malaysia, December 2018.

[227] B. Kim, J. Ha, F. C. Park, and P. E. Dupont, "Optimizing curvature sensor placement for fast, accurate shape sensing of continuum robots," in Proceedings of the IEEE International Conference on Robotics and Automation (ICRA), pp. 5374-5379, Hong Kong, China, May 2014.

[228] J. Li, Z. Teng, J. Xiao, A. Kapadia, A. Bartow, and I. Walker, "Autonomous continuum grasping," in Proceedings of the IEEE/RSJ International Conference on Intelligent Robots and Systems, pp. 4569-4576, Tokyo, Japan, November 2013.

[229] J. M. Croom, D. C. Rucker, J. M. Romano, and R. J. Webster, "Visual sensing of continuum robot shape using self-organizing maps," in Proceedings of the IEEE International Conference on Robotics and Automation, pp. 4591-4596, Anchorage, Alaska, May 2010.

[230] M. Hannan and I. Walker, "Vision based shape estimation for continuum robots," in Proceedings of the IEEE International Conference on Robotics and Automation (Cat. No. 03CH37422), vol. 3, pp. 3449-3454, Taipei, Taiwan, September 2003.

[231] B. A. Jones and I. D. Walker, "Three-dimensional modeling and display of continuum robots," in Proceedings of the IEEE/RSJ International Conference on Intelligent Robots and Systems, pp. 5872-5877, Beijing, China, October 2006.

[232] V. K. Chitrakaran, A. Behal, D. M. Dawson, and I. D. Walker, "Setpoint regulation of continuum robots using a fixed camera," Robotica, vol. 25, no. 5, pp. 581-586, 2007.

[233] D. Cojocaru and R. T. Tănasie, "Graphic simulation for camera calibration in visual-servoing applications," in Proceedings of the International Conference on Signal Processing, Computational Geometry and Artificial Vision, pp. 150-156, Rhodes, Greece, August 2008.

[234] B. Weber, P. Zeller, and K. Kühnlenz, "Multi-camera based real-time configuration estimation of continuum robots," IEEE/RSJ International Conference on Intelligent Robots and Systems, pp. 3350-3355, 2012.

[235] S. Sareh, Y. Noh, M. Li, T. Ranzani, H. Liu, and K. Althoefer, "Macrobend optical sensing for pose measurement in soft robot arms," Smart Materials and Structures, vol. 24, no. 12, p. 125024, 2015.

[236] Md Billah, Md R. Khan, and A. A. Shafie, "Modeling and simulation of electroactive polymer robotic actuator," in 
Proceedings of the IEEE ICIT, pp. 502-507, Seville, Spain, March 2015.

[237] O. Medina, A. Shapiro, and N. Shvalb, "Resistor-based shape sensor for a spatial flexible manifold," IEEE Sensors Journal, vol. 17, no. 1, pp. 46-50, 2016.

[238] J. Zhao, J. Zhang, D. McCoul, Y. Cui, and X. Lan, "A soft biomimetic module of elephant trunk driven by dielectric elastomers," in Proceedings of the IEEE International Conference on Robotics and Biomimetics (ROBIO), pp. 349-354, Kuala Lumpur, Malaysia, December 2018.

[239] J. Avery, M. Runciman, A. Darzi, and G. P. Mylonas, "Shape sensing of variable stiffness soft robots using electrical impedance tomography," in Proceedings of the International Conference on Robotics and Automation (ICRA), pp. 90669072, Montreal, Canada, May 2019.

[240] B. Kwak and J. Bae, "Development of a four-bar linkage integrated with a polypyrrole actuator and a resistive sensor toward biomimetic pleopods," in Proceedings of the IEEE International Conference on Soft Robotics (RoboSoft), pp. 698-703, Seoul, South Korea, April 2019. 